\title{
Composição florística e estrutura de uma unidade de manejo florestal sustentável na Floresta Nacional do Tapajós, Pará
}

\author{
Fábio Guimarães GONÇALVES ${ }^{1}$, João Roberto dos SANTOS²
}

\begin{abstract}
RESUMO
Neste trabalho são discutidos aspectos da composição florística e da estrutura de um povoamento de floresta ombrófila densa submetido a práticas de exploração madeireira de impacto reduzido. O estudo foi conduzido numa unidade de manejo florestal com aproximadamente 3.200 ha, instalada na porção norte da Floresta Nacional do Tapajós (estado do Pará), onde foram extraídos, em média, $23,7 \mathrm{~m}^{3}$ de madeira por hectare. Para representar a variabilidade existente na área experimental, foram estabelecidas aleatoriamente seis parcelas amostrais de um hectare em diferentes quadras de exploração. As análises florístico-estruturais foram realizadas em duas escalas distintas com vistas a atender objetivos específicos: (a) em nível de unidade de manejo, para uma caracterização global do povoamento florestal no qual serão baseados estudos subseqüentes; e (b) em nível de parcela amostral, para subsidiar o estudo de dados de sensoriamento remoto frente às variaçōes florísticoestruturais observadas. $\mathrm{O}$ conjunto de resultados obtidos indicou que a unidade de manejo florestal apresenta uma elevada diversidade florística no componente arbóreo (índice de Shannon-Weaver igual a 4,22). Observou-se que o povoamento é caracterizado pela concentração de uma grande quantidade de indivíduos e espécies em poucas famílias botânicas e por um número elevado de espécies localmente raras. A análise das variaçōes florístico-estruturais entre parcelas amostrais evidenciou diferenças estatísticas significativas quanto à diversidade e a similaridade de espécies e quanto a valores médios de altura total. Adicionalmente, observou-se certa variabilidade nos padróes estruturais em termos de distribuição diamétrica e de valores estimados de volume comercial de madeira.
\end{abstract}

PALAVRAS-CHAVE: Inventário florestal, Fitossociologia, Exploração seletiva, Amazônia.

\section{Floristic composition and structure of a sustainable forest management unit at Tapajos National Forest, Para, Brazil}

\begin{abstract}
In this work we discuss aspects of the floristic composition and structure of a stand of dense tropical rain forest subjected to low-impact logging practices. We conducted the study in a 3,200 ha forest management unit located in the north portion of the Tapajos National Forest (Para, Brazil), where a mean timber volume of $23.7 \mathrm{~m}^{3} \cdot \mathrm{ha}^{-1}$ had been extracted. To represent the variability existing within the experimental area, we randomly selected six 1 ha sample plots in different exploitation blocks. The floristic-structural analyses were made at two distinct scales: (a) at a management unit level, for a global characterization of the forest stand in which later studies will be performed; and (b) at a sample plot level, to aid the study of remote sensing data, given the observed floristic-structural variations. The results showed that the forest management unit hosts a high floristic diversity (Shannon-Weaver index equals 4.22). The stand is characterized by a high individuals/species concentration in few botanical families, and by a high number of locally rare species. Analysis of the floristic-structural variations between sample plots showed statistically significant differences in species diversity and similarity, and in mean total height values. In addition, we noted significant variability in the structural metrics such as the distribution of diameters and the estimated timber volume.
\end{abstract}

KEYWORDS: Forest inventory, Phytossociology, Selective logging, Amazon.

1 Department of Forest Science, Oregon State University, Corvallis, OR 97331, USA. e-mail: fabio.goncalves@oregonstate.edu

2 Divisão de Sensoriamento Remoto, Instituto Nacional de Pesquisas Espaciais, São José dos Campos, SP 12227-010, Brasil. e-mail: jroberto@dsr.inpe.br 


\section{INTRODUÇÃO}

O entendimento quantitativo da participação das florestas tropicais no ciclo global do carbono está condicionado, em parte, à disponibilidade de metodologias eficientes para a estimativa acurada de biomassa em grandes extensões territoriais. Na Amazônia brasileira, cuja área representa um terço das florestas tropicais do mundo, cerca de 50\% da biomassa florestal é constituída por carbono (Brown et al., 1992; Higuchi \& Carvalho, 1994; Carvalho et al., 1995). Dessa forma, a biomassa representa uma quantidade considerável de $\mathrm{CO}_{2}$ que pode ser adicionada e/ou removida da atmosfera com as alterações realizadas sobre a cobertura, uso e manejo destes ecossistemas florestais (Brown, 1997).

O processo de conversão das florestas amazônicas em áreas de atividade agrícola tem sido extensamente investigado nos últimos anos, incluindo o estudo dos impactos provocados nos ciclos globais e nos processos climatológicos (Nobre et al., 1991). Entretanto, ainda existe pouco conhecimento sobre a extensão dos impactos provenientes da atividade de exploração madeireira, a qual é raramente praticada de modo sustentável (Barros \& Veríssimo, 2002; Asner et al., 2005). Assim, a temática tem despertado interesse particular nos estudos florestais atuais, sobretudo quanto às modificações empregadas na estrutura florestal e nos estoques de carbono (Uhl et al., 1991; Veríssimo et al., 1992; Nepstad et al., 1999).

Dados de sensoriamento remoto têm sido amplamente empregados na aquisição de informações em aplicações que envolvem grandes extensóes territoriais, a exemplo do monitoramento do desflorestamento da Amazônia (INPE, 2007) e dos inventários florestais nacionais (Hyyppa et al., 2000). A capacidade de fornecimento de informaçōes quantitativas precisas, em alta resolução espacial e temporal, torna esse ferramental importante no estudo e gerenciamento da paisagem florestal (Foody et al., 2003). Conseqüentemente, o sensoriamento remoto tem papel fundamental na estimativa de biomassa, conforme vem sendo demonstrado em algumas publicaçōes (e.g., Le Toan et al., 1992; Dobson et al., 1995; Luckman et al., 1997; Hoekman \& Quiñones, 2000; Santos et al., 2003).

O Instituto Nacional de Pesquisas Espaciais (INPE), através da Coordenação-Geral de Observação da Terra (OBT), vem desenvolvendo uma série de estudos científicos na Floresta Nacional do Tapajós, com o intuito de investigar o potencial de tecnologias espaciais para inventário e monitoramento de florestas tropicais. Como etapa do trabalho desenvolvido por esse instituto, foi conduzido um inventário florestal, em setembro de 2005, num povoamento de floresta ombrófila densa submetido a práticas de exploração madeireira. Nesse contexto, o presente trabalho tem por objetivo apresentar aspectos da composição florística e da estrutura do componente arbóreo nessa área experimental. Tal objetivo se insere numa linha investigativa de maior amplitude, a qual busca explorar a capacidade de dados-radar na estimativa volumétrica de áreas florestais, tendo em vista o monitoramento da atividade madeireira na região amazônica.

É importante notar que a Floresta Nacional do Tapajós tem sido objeto de inúmeros estudos florestais desde a sua criação (e.g., Dubois, 1976; Cailliez, 1977; Barros, 1980; IBDF, 1983; Silva et al., 1985; Guimarães \& Pyle, 1999; Espírito-Santo et al., 2005; Oliveira, 2005). Porém, grande parte se concentrou em áreas não manejadas, visando caracterizar o potencial madeireiro para subsidiar propostas de manejo sustentado (IBAMA, 2004). Desse modo, pouco se explorou em termos de características florístico-estruturais de áreas já manejadas (e.g., Oliveira, 2005), as quais constituem o foco do presente trabalho.

\section{MATERIAL E MÉTODOS}

\section{CARACTERIZAÇÃO DA ÁREA DE ESTUDO}

A Floresta Nacional do Tapajós está localizada no Estado do Pará, ao longo da rodovia Cuiabá-Santarém (BR-163), na porção central da floresta amazônica (Figura 1). Situada

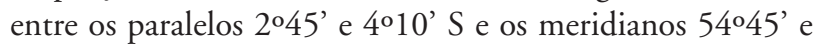
55030' W, abrange parte dos municípios de Belterra, Aveiro, Rurópolis e Placas, estendendo-se por uma área aproximada de $545.000 \mathrm{ha}$. Administrada pelo Instituto Brasileiro do Meio Ambiente e dos Recursos Naturais Renováveis (IBAMA), apresenta como objetivo básico o uso múltiplo dos recursos florestais e a pesquisa científica, com ênfase em métodos para a exploração sustentável (Brasil, 2002).

De acordo com IBAMA (2004), o clima da região é do tipo Ami (classificação de Köppen), com temperatura média anual de $25,5^{\circ} \mathrm{C}$. A concentração de chuvas ocorre entre janeiro e maio, resultando em uma precipitação média anual de $1.820 \mathrm{~mm}$. O relevo local, pouco acidentado, se apresenta com topografia de suavemente ondulada a ondulada, predominando na área o solo do tipo Latossolo Amarelo Distrófico. A vegetação é classificada como Floresta Ombrófila Densa (Veloso, 1991), caracterizando-se pela dominância de indivíduos arbóreos de grande porte e pela abundância de lianas lenhosas, palmeiras e epífitas. Variações no relevo local resultam na ocorrência de tipologias florestais diferenciadas, as quais se apresentam com dossel uniforme ou com árvores emergentes.

Este estudo foi conduzido numa unidade de manejo florestal com aproximadamente 3.200 ha, instalada na porção norte da Floresta Nacional do Tapajós (Figura 1), para a produção sustentável de madeira em tora (IBAMA/PNUD, 1997). Nessa unidade foram estabelecidas três quadras de exploração, que foram subdivididas num total de 38 blocos com áreas entre 10 e 100 ha. Entre 1999 e 2003 foi extraído 
um volume médio de $23,7 \mathrm{~m}^{3}$.ha $\mathrm{a}^{-1}$ de madeira dos blocos, o que representou uma densidade média de exploração de 3,3 árvores.ha ${ }^{-1}$. De acordo com IBAMA/PNUD (1997), nessa unidade de manejo florestal está previsto um ciclo de corte de 18 a 22 anos, esperando-se um incremento médio anual no volume de $2,5 \mathrm{~m}^{3} \cdot \mathrm{ha}^{-1}$ (valor esperado em função das práticas de manejo adotadas).

\section{AQUISIÇÃO E TRATAMENTO DOS DADOS}

O inventário florestal foi realizado em setembro de 2005, simultaneamente à aquisição dos dados de sensoriamento remoto, de forma a subsidiar o conhecimento da composição florística e da estrutura florestal na área de realização do experimento. Para representar a variabilidade florísticoestrutural existente na unidade de manejo florestal foram estabelecidas aleatoriamente duas parcelas temporárias de 1 ha $(100 \times 100 \mathrm{~m})$ em cada quadra de exploração, resultando em uma área amostral total de 6 ha. Essas parcelas foram delimitadas em campo com base no método proposto por Mueller-Dombois \& Ellenberg (1974) e posicionadas geograficamente com o auxílio de uma estação total e do Sistema de Posicionamento Global (GPS).

Nas parcelas amostrais foi realizado o inventário de todos os indivíduos arbóreos com diâmetro à altura do peito (DAP) maior ou igual a $10 \mathrm{~cm}$. Além do DAP (obtido com uma fita diamétrica), foram realizadas estimativas visuais da altura comercial (HC) e da altura total (HT) para cada árvore inventariada. Em adição, foram mensuradas as dimensōes horizontais da copa (semi-eixos) e obtidas medidas da coordenada local das árvores com o uso de uma trena métrica. $\mathrm{O}$ volume comercial de madeira (VCM) das árvores foi estimado pela equação alométrica:

$$
V C M=0,0775+0,5179 \cdot\left(D A P^{2} \cdot H C\right)
$$

em que VCM é o volume geométrico do tronco em metros cúbicos, excluindo-se a casca e todos os galhos; DAP é o diâmetro do tronco em metros, medido à altura de $1,3 \mathrm{~m}$

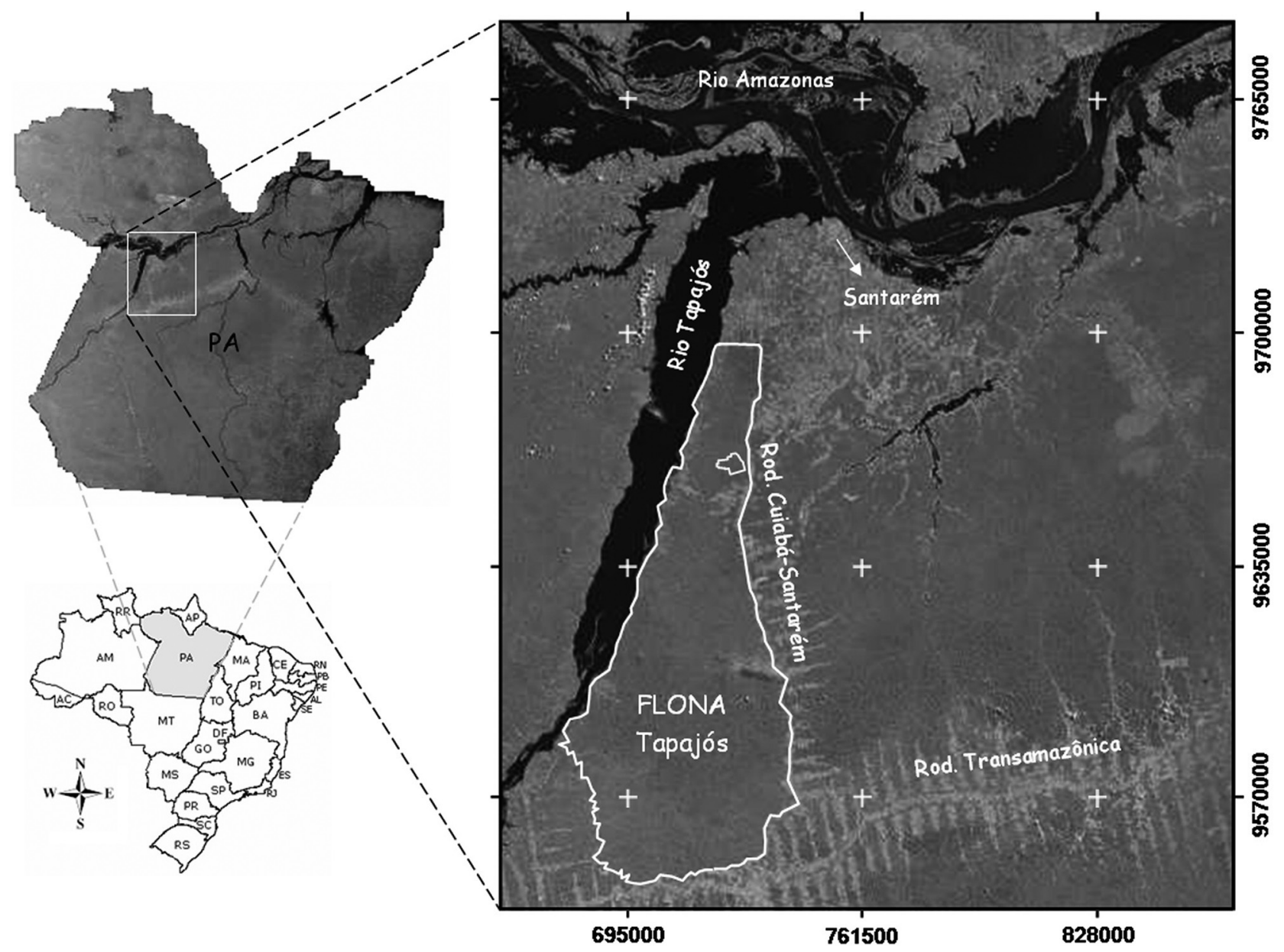

Figura 1 - Localização geográfica da Floresta Nacional do Tapajós, com destaque na unidade de manejo florestal (polígono interno). Ao fundo, imagens TM e/ou ETM + obtidas entre 1991 e 1999 (disponível em: http://www.cdbrasil.cnpm.embrapa.br). 


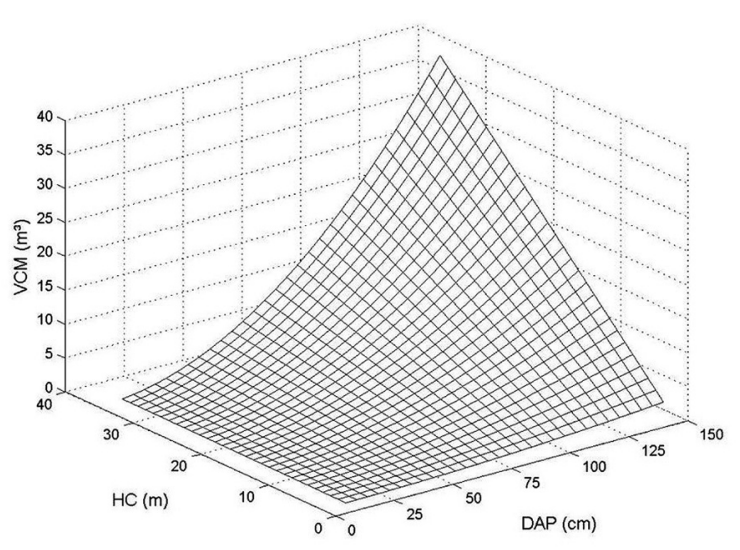

Figura 2 - Superfície de resposta volumétrica da equação empregada para a estimativa do VCM na unidade de manejo florestal.

do solo; e HC é a altura comercial em metros, medida até a primeira bifurcação dos galhos (Queiroz, 1984). Na Figura 2 é possível observar, como exemplo, a superfície de resposta volumétrica fornecida pela Equação 1, como função de diferentes valores de entrada de DAP e HC.

Com o objetivo de melhorar as estimativas visuais realizadas para as alturas das árvores, foram registradas aleatoriamente 277 mensurações adicionais com o emprego de um clinômetro eletrônico. A partir deste conjunto de dados foi ajustado um modelo de regressão simples, em que a medida $\mathrm{da}$ altura das árvores realizada por estimativa visual $\left(\mathrm{H}_{\mathrm{EV}}\right)$ foi utilizada para explicar a medida obtida com o clinômetro eletrônico $\left(\mathrm{H}_{\mathrm{CE}}\right)$ :

$H_{C E}=e^{0,1845} H_{E V}^{0,9480}$

Este modelo de regressão apresentou coeficiente de determinação igual a 0,91 e erro padrão da estimativa igual a $6,1 \%$, sendo empregado posteriormente para uma estimativa mais acurada das alturas das demais árvores inventariadas.

A identificação botânica das espécies encontradas foi realizada primeiramente em campo, pelo nome popular, com o auxílio de um identificador botânico familiarizado com a flora da região. Posteriormente, foi realizada a associação dos nomes populares aos respectivos nomes científicos com o apoio de listas de espécies publicadas em outros trabalhos científicos (i.e., Guimarães \& Pyle, 1999; Oliveira, 2005) ${ }^{1}$. Todos os nomes científicos e detalhes bibliográficos básicos associados foram confirmados com a utilização do banco de dados International Plant Names Index - IPNI (http://www. ipni.org). Após a identificação, as espécies foram agrupadas por famílias, conforme o sistema de classificação do Angiosperm Phylogeny Group (APG, 1998).

${ }^{1}$ É importante notar que estes trabalhos científicos de referência também foram realizados na Floresta Nacional do Tapajós, a partir de dados coletados com 0 auxílio do mesmo identificador botânico.
Com a finalidade de facilitar a integração e análise dos dados e possibilitar a realização de consultas espaciais, foi utilizado o ambiente de um Sistema de Informaçōes Geográficas (SIG) para a implementação de um banco de dados com todas as informações descritas nesta seção. A Figura 3 é utilizada aqui para auxiliar a explicação do procedimento adotado no georreferenciamento de cada árvore inventariada.

Seja $(x, y)$ o sistema de coordenadas local - estabelecido em campo com trena métrica para a mensuração da posição relativa das árvores - e $(X, Y)$ o sistema de coordenadas UTM, ambos em metros. Os pontos $P_{1}\left(X_{1}, Y_{1}\right)$ e $P_{2}\left(X_{2}, Y_{2}\right)$ correspondem às coordenadas UTM obtidas com o sistema GPS no posicionamento de cada parcela amostral. A partir destes pontos foi calculado o ângulo $\theta$ formado entre os dois sistemas planos. Assim, para uma dada árvore $A$, a transformação das coordenadas locais em coordenadas do sistema UTM foi obtida com a aplicação da equação (Mather, 1999):

$$
\left[\begin{array}{l}
X \\
Y
\end{array}\right]=\left[\begin{array}{c}
X_{1} \\
Y_{1}
\end{array}\right]+R\left[\begin{array}{l}
x \\
y
\end{array}\right], \text { com }
$$

$$
\left\{\begin{array}{l}
R=\left[\begin{array}{cc}
\cos \theta & \operatorname{sen} \theta \\
-\operatorname{sen} \theta & \cos \theta
\end{array}\right], \text { for no sentido anti-horário } \\
R=\left[\begin{array}{cc}
\cos \theta & -\operatorname{sen} \theta \\
\operatorname{sen} \theta & \cos \theta
\end{array}\right], \text { fo a rotação do sentistema }(x, y)
\end{array}\right.
$$

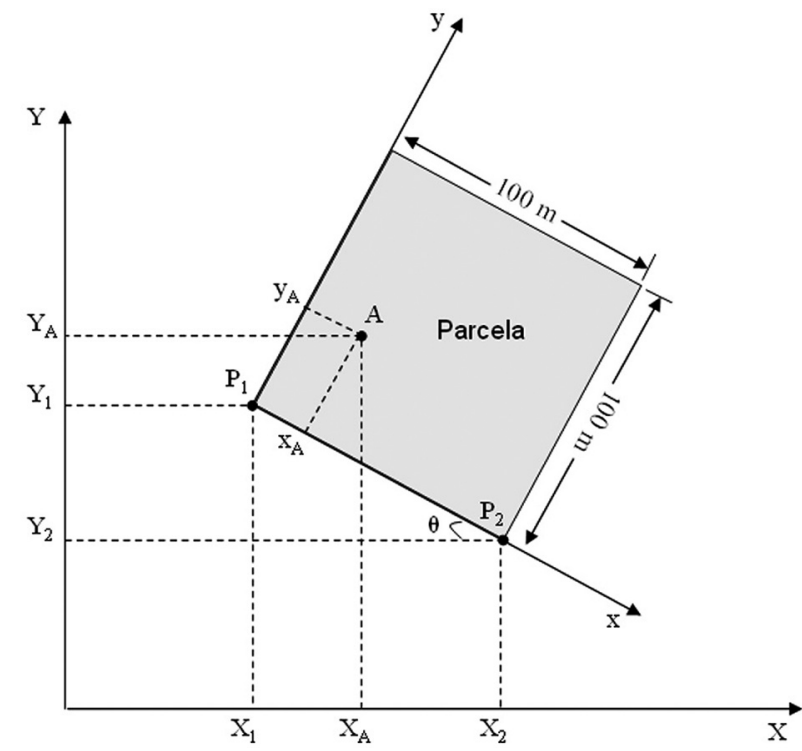

Figura 3 - Representação esquemática do procedimento de georreferenciamento das árvores inventariadas nas parcelas amostrais. 


\section{MÉTODOS DE ANÁLISE}

Neste trabalho foram conduzidas análises florísticoestruturais em duas escalas distintas: (a) em nível de unidade de manejo, para uma caracterização global do povoamento florestal no qual serão baseados os estudos subseqüentes; e (b) em nível de parcela amostral, para subsidiar o estudo dos dados sensoriados frente às variaçôes florístico-estruturais observadas. Nos próximos itens são apresentados com detalhes os métodos empregados nos dois casos distintos.

\section{CARACTERIZAÇÃO DO POVOAMENTO FLORESTAL}

A suficiência amostral do inventário florestal foi avaliada com base na curva espécie-área. Para a construção desta curva, cada parcela amostral de 1 ha foi decomposta em 25 sub-parcelas de $400 \mathrm{~m}^{2}(20 \times 20 \mathrm{~m})$. As 150 sub-parcelas resultantes foram ordenadas por amostragem aleatória e a sequiência foi utilizada para a contagem do aparecimento de novas espécies. O ponto de saturação do número acumulado de espécies foi determinado por análise visual da função ajustada à curva espécie-área.

Técnicas de análise quantitativa foram empregadas para a realização de uma abordagem criteriosa da composição florística na área experimental. A diversidade de espécies foi estimada, conforme sugerido por Magurran (1988), com o índice de Shannon-Weaver $(H)$ e com a equabilidade de Pielou (/):

$H^{\prime}=-\sum_{i=1}^{S}\left[p_{i} \ln \left(p_{i}\right)\right]$, com $p_{i}=\frac{n_{i}}{N}$

$J=\frac{H^{\prime}}{\ln (S)}$

em que $n_{i}$ é o número de árvores da espécies $i$; $N$ é o número total de árvores; e $S$ é o número total de espécies amostradas.

Para a realização de um diagnóstico da estrutura horizontal do povoamento florestal foram incluídas as estimativas de densidade, dominância e freqüência de cada espécie, conforme descrito por Mueller-Dombois \& Ellenberg (1974):

$$
\begin{gathered}
D A_{i}=\frac{n_{i}}{A_{h a}} \quad \text { e } \quad D R_{i}=100 \frac{D A_{i}}{\sum_{i=1}^{S} D A_{i}} \\
D o A_{i}=\frac{G_{i}}{A_{h a}} \quad \text { e } \quad \operatorname{DoR}_{\mathrm{i}}=100 \frac{G_{i}}{\sum_{i=1}^{S} G_{i}}
\end{gathered}
$$

$$
F A_{i}=100 \frac{u_{i}}{u_{t}} \quad \text { e } \quad \mathrm{FR}_{\mathrm{i}}=100 \frac{F A_{i}}{\sum_{i=1}^{S} F A_{i}}
$$

em que $D, D o$, e $F$ correspondem, respectivamente, à densidade, dominância e freqüência, absoluta $(A)$ e relativa $(R)$, da espécie $i$; $n_{i}$ é o número de árvores da espécie $i$; $A_{h a}$ é a área total amostrada em hectares; $S$ é o número total de espécies amostradas; $G_{i}$ é a área basal da espécie $i$ em metros quadrados; $u_{i}$ é o número de parcelas amostrais nas quais a espécie $i$ ocorre; e $u_{t}$ é o número total de parcelas amostrais. A partir da soma dos valores relativos dessas três estimativas foi calculado o índice do valor de importância (IVI), introduzido por Curtis \& McIntosh (1951).

As 50 espécies florestais com maior IVI foram classificadas quanto ao potencial de aproveitamento no mercado madeireiro (comerciais, potenciais ou não comerciais) e comportamento ecológico (pioneiras ou tolerantes), segundo os critérios adotados por Oliveira (2005). As espécies cujas informações não estavam disponíveis foram classificadas como "sem caracterização".

\section{CARACTERIZAÇÃO DAS PARCELAS AMOSTRAIS}

Assim como na caracterização do povoamento florestal, a diversidade de espécies foi estimada para cada parcela amostral com a utilização do índice de Shannon-Weaver. O teste $t$, proposto por Hutcheson (1970), foi utilizado para avaliar se as parcelas apresentaram diferenças significativas quanto à diversidade. Em adição, foi determinada a similaridade florística entre as diferentes parcelas amostrais com a utilização do índice de Jaccard $\left(S_{i j}\right)$ (Magurran, 1988):

$S_{i j}=\frac{c}{a+b+c}$

em que $a$ é o número de espécies exclusivas na parcela $i ; b$ é o número de espécies exclusivas na parcela $j$; e $c$ é o número de espécies comuns entre as parcelas $i$ e $j$. Os valores obtidos foram interpretados através de agrupamentos por média de grupo (UPGMA), conforme sugerido por Sneath \& Sokal (1973).

Além da análise da diversidade e da similaridade florística, foi realizada a caracterização estrutural das parcelas amostrais empregando-se duas variáveis biofísicas fundamentais: DAP e HT. Para detectar diferenças significativas entre a estrutura destas parcelas (tratamentos), foi empregada a técnica de análise de variância (ANOVA) e o teste de comparação múltipla de Tukey (Hair et al., 1998). Na condução da ANOVA, a exemplo da construção da curva espécie-área, cada parcela amostral foi decomposta em 25 sub-parcelas. Para evitar a autocorrelação espacial dos dados, foram selecionadas, 
por amostragem sistemática, 13 sub-parcelas de cada grupo de 25. Nessas sub-parcelas foram computados os valores médios de DAP e HT, compondo-se assim as observações dos tratamentos.

Na ANOVA são feitas três suposições principais a respeito do conjunto de dados: (1) cada observação é independente das demais; (2) a variável dependente deve ser normalmente distribuída nos tratamentos; e (3) as variâncias dos diferentes tratamentos devem ser iguais. Para avaliar essas suposiçōes foram utilizados, respectivamente, os testes de Moran (Anselin, 1996), Shapiro-Wilk (Shapiro et al., 1968) e Bartlett (Winer et al., 1991).

\section{RESULTADOS E DISCUSSÃO}

\section{CARACTERIZAÇÃO DO POVOAMENTO FLORESTAL}

Nos seis hectares amostrados no inventário florestal foram encontrados 2.213 indivíduos arbóreos, distribuídos em 44 famílias botânicas e 186 espécies. Desse total, quatro indivíduos arbóreos, correspondentes a quatro espécies não identificadas, foram agrupados em uma única família denominada "Indeterminadas". A curva espécieárea, apresentada na Figura 4, indicou uma tendência à estabilização do aparecimento de novas espécies a partir de uma área amostral de aproximadamente 2 ha. Todavia, devido à grande heterogeneidade florística da área, a estabilização não se confirmou até o limite de 6 ha. Em função da considerável redução no aparecimento de espécies no referido intervalo, a intensidade amostral do inventário (6 ha) foi considerada suficiente para representar a composição florística da área experimental. Esse resultado reforça a necessidade de grandes extensōes amostrais em inventários florestais na Amazônia, conforme discutido por Jardim \& Hosokawa (1986).

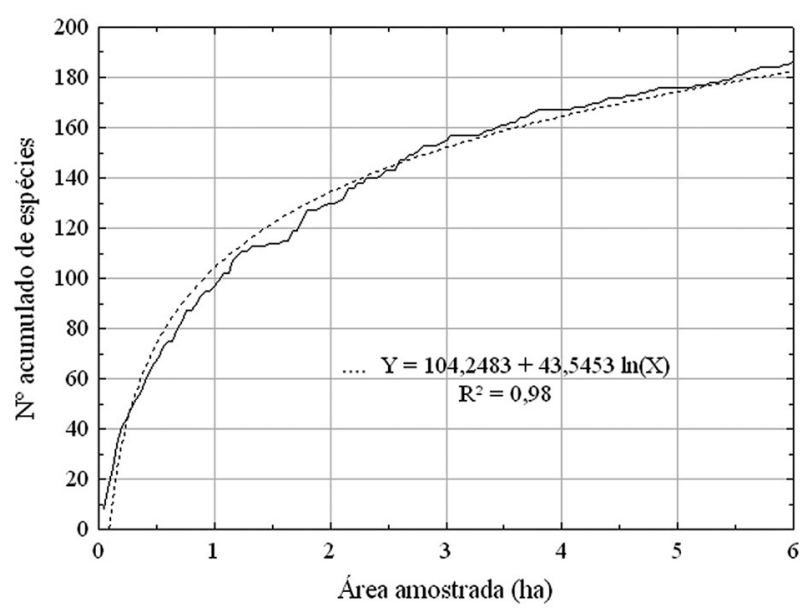

Figura 4 - Curva espécie-área obtida com a amostragem empregada no inventário florestal.
O valor obtido para o índice de Shannon-Weaver $\left(H^{\prime}=\right.$ $4,22)$ indicou um alto grau de incerteza associado à previsão da espécie a qual pertenceria uma dada árvore selecionada ao acaso no conjunto amostral. A equabilidade de Pielou apresentou valor de 0,81 , confirmando a existência de uma elevada diversidade florística no componente arbóreo do povoamento estudado. Os resultados obtidos foram compatíveis com aqueles relatados em outros estudos conduzidos na Floresta Nacional do Tapajós (e.g., Barros, 1980; Espírito-Santo et al., 2005; Oliveira, 2005).

$\mathrm{Na}$ Figura 5 são apresentados os parâmetros fitossociológicos das dez famílias amostradas com maior IVI. O povoamento florestal estudado foi caracterizado pela concentração de uma grande quantidade de indivíduos arbóreos em poucas famílias botânicas. Do total de 2.213 indivíduos inventariados, $1.720(78 \%)$ foram representados somente pelas famílias apresentadas na Figura 5.

Em termos de distribuição da riqueza florística foi constatado um padrão semelhante. Um conjunto de apenas oito famílias contribuiu com mais de $50 \%$ do total de espécies encontradas, a saber: Fabaceae (37), Moraceae (13), Lecythidaceae (10), Apocynaceae (8), Euphorbiaceae (8), Lauraceae (7), Meliaceae (7) e Malvaceae (6). Em adição, observou-se que $30 \%$ das famílias contribuíram com apenas uma espécie.

Na Tabela 1 são apresentados os parâmetros fitossociológicos de todas as espécies amostradas, por ordem alfabética de famílias e em ordem decrescente de índice do valor de importância relativo (IVI\%). Pela análise da Tabela 1 é possível observar que as cinco espécies com maior valor de importância no povoamento foram: Pouteria sp. (abiu), Protium apiculatum Swart (breu), Rinorea guianensis (Aubl.) Kuntze (aquariquarana), Eperua bijuga Mart. ex Benth. (cocão) e Eschweilera blanchetiana Miers. (matamatá preto).

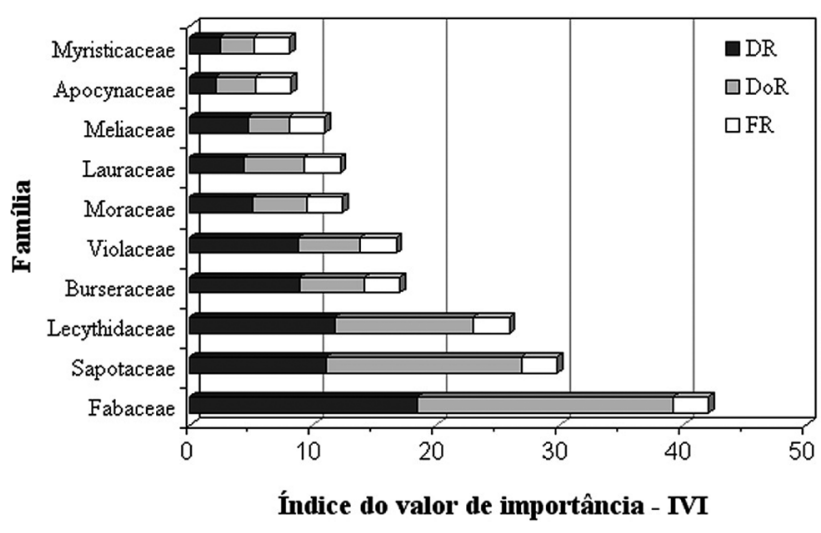

Figura 5 - Parâmetros fitossociológicos das 10 famílias amostradas com maior IVI. DR, DoR, e FR correspondem, respectivamente, à densidade, dominância e freqüência relativas. 
Tabela 1 - Relação das espécies arbóreas inventariadas na unidade de manejo florestal, com o respectivo número de árvores (N), densidade absoluta (DA), densidade relativa (DR), dominância absoluta (DoA), dominância relativa (DoR), frequêência absoluta ( $F A)$, freqüência relativa ( $F R$ ) e índice do valor de importância relativo (IVI\%), por ordem alfabética de famílias e em ordem decrescente de IVI\%.

\begin{tabular}{|c|c|c|c|c|c|c|c|c|}
\hline Famílias e Espécies & $\mathbf{N}$ & DA & DR & DoA & DoR & FA & FR & IVI\% \\
\hline \multicolumn{9}{|l|}{ Anacardiaceae } \\
\hline Astronium gracile Engl. & 4 & 0,7 & 0,18 & 0,344 & 1,53 & 50,0 & 0,52 & 0,74 \\
\hline Tapirira guianensis Aubl. & 9 & 1,5 & 0,41 & 0,094 & 0,42 & 100,0 & 1,03 & 0,62 \\
\hline \multicolumn{9}{|l|}{ Annonaceae } \\
\hline Duguetia echinophora R.E.Fr. & 35 & 5,8 & 1,58 & 0,164 & 0,73 & 100,0 & 1,03 & 1,11 \\
\hline Guatteria poeppigiana Mart. & 19 & 3,2 & 0,86 & 0,229 & 1,02 & 83,3 & 0,86 & 0,91 \\
\hline Annona montana Macfad. \& R.E.Fr. & 5 & 0,8 & 0,23 & 0,017 & 0,07 & 50,0 & 0,52 & 0,27 \\
\hline Xylopia benthami R.E.Fr. & 3 & 0,5 & 0,14 & 0,009 & 0,04 & 33,3 & 0,34 & 0,17 \\
\hline Guatteria ovalifolia R.E.Fr. & 2 & 0,3 & 0,09 & 0,008 & 0,04 & 33,3 & 0,34 & 0,16 \\
\hline \multicolumn{9}{|l|}{ Apocynaceae } \\
\hline Geissospermum sericeum Benth. \& Hook.f. ex Miers & 26 & 4,3 & 1,17 & 0,358 & 1,59 & 100,0 & 1,03 & 1,27 \\
\hline Aspidosperma rigidum Rusby & 7 & 1,2 & 0,32 & 0,268 & 1,19 & 66,7 & 0,69 & 0,73 \\
\hline Lacmellea aculeata (Ducke) Monach. & 4 & 0,7 & 0,18 & 0,022 & 0,10 & 66,7 & 0,69 & 0,32 \\
\hline Malouetia sp. & 3 & 0,5 & 0,14 & 0,017 & 0,07 & 50,0 & 0,52 & 0,24 \\
\hline Aspidosperma desmanthum Benth. & 3 & 0,5 & 0,14 & 0,018 & 0,08 & 33,3 & 0,34 & 0,19 \\
\hline Himatanthus sucuuba (Spruce) Woodson & 1 & 0,2 & 0,05 & 0,026 & 0,12 & 16,7 & 0,17 & 0,11 \\
\hline Aspidosperma duckei Huber ex Ducke & 1 & 0,2 & 0,05 & 0,014 & 0,06 & 16,7 & 0,17 & 0,09 \\
\hline Ambelania sp. & 1 & 0,2 & 0,05 & 0,004 & 0,02 & 16,7 & 0,17 & 0,08 \\
\hline \multicolumn{9}{|l|}{ Araliaceae } \\
\hline Didymopanax morototoni (Aubl.) Decne. \& Planch. & 2 & 0,3 & 0,09 & 0,054 & 0,24 & 33,3 & 0,34 & 0,22 \\
\hline \multicolumn{9}{|l|}{ Arecaceae } \\
\hline Orbignya speciosa Barb.Rodr. & 4 & 0,7 & 0,18 & 0,054 & 0,24 & 16,7 & 0,17 & 0,20 \\
\hline Astrocaryum sp. & 2 & 0,3 & 0,09 & 0,033 & 0,15 & 33,3 & 0,34 & 0,19 \\
\hline Maximiliana martiana Karst. & 2 & 0,3 & 0,09 & 0,019 & 0,09 & 16,7 & 0,17 & 0,12 \\
\hline \multicolumn{9}{|l|}{ Bignoniaceae } \\
\hline Jacaranda copaia D.Don & 15 & 2,5 & 0,68 & 0,260 & 1,16 & 83,3 & 0,86 & 0,90 \\
\hline Tabebuia impetiginosa Standl. & 1 & 0,2 & 0,05 & 0,080 & 0,36 & 16,7 & 0,17 & 0,19 \\
\hline \multicolumn{9}{|l|}{ Bixaceae } \\
\hline Bixa arborea Huber & 3 & 0,5 & 0,14 & 0,091 & 0,41 & 50,0 & 0,52 & 0,35 \\
\hline \multicolumn{9}{|l|}{ Bombacaceae } \\
\hline Quararibea guianensis Aubl. & 10 & 1,7 & 0,45 & 0,043 & 0,19 & 83,3 & 0,86 & 0,50 \\
\hline Bombax sp. & 2 & 0,3 & 0,09 & 0,081 & 0,36 & 16,7 & 0,17 & 0,21 \\
\hline Bombax paraense Ducke & 1 & 0,2 & 0,05 & 0,004 & 0,02 & 16,7 & 0,17 & 0,08 \\
\hline \multicolumn{9}{|l|}{ Boraginaceae } \\
\hline Cordia alliodora (Ruíz \& Pav.) Cham. & 16 & 2,7 & 0,72 & 0,079 & 0,35 & 83,3 & 0,86 & 0,64 \\
\hline Cordia bicolor A.DC. in DC. & 5 & 0,8 & 0,23 & 0,043 & 0,19 & 50,0 & 0,52 & 0,31 \\
\hline Cordia goeldiana Huber & 1 & 0,2 & 0,05 & 0,034 & 0,15 & 16,7 & 0,17 & 0,12 \\
\hline \multicolumn{9}{|l|}{ Burseraceae } \\
\hline Protium apiculatum Swart & 188 & 31,3 & 8,50 & 1,097 & 4,87 & 100,0 & 1,03 & 4,80 \\
\hline Protium subserratum Engl. & 5 & 0,8 & 0,23 & 0,022 & 0,10 & 66,7 & 0,69 & 0,34 \\
\hline Trattinickia rhoifolia Willd. & 5 & 0,8 & 0,23 & 0,051 & 0,23 & 50,0 & 0,52 & 0,32 \\
\hline \multicolumn{9}{|l|}{ Caricaceae } \\
\hline Jacaratia spinosa var. digitata (Poepp.) A.DC. & 3 & 0,5 & 0,14 & 0,019 & 0,08 & 33,3 & 0,34 & 0,19 \\
\hline \multicolumn{9}{|l|}{ Caryocaraceae } \\
\hline Caryocar villosum Pers. & 1 & 0,2 & 0,05 & 0,158 & 0,70 & 16,7 & 0,17 & 0,31 \\
\hline Caryocar glabrum Pers. & 3 & 0,5 & 0,14 & 0,009 & 0,04 & 50,0 & 0,52 & 0,23 \\
\hline
\end{tabular}




\begin{tabular}{|c|c|c|c|c|c|c|c|c|}
\hline Famílias e Espécies & $\mathbf{N}$ & DA & DR & DoA & DoR & FA & FR & IVI\% \\
\hline \multicolumn{9}{|l|}{ Cecropiaceae } \\
\hline Pourouma longipendula Ducke & 14 & 2,3 & 0,63 & 0,206 & 0,92 & 83,3 & 0,86 & 0,80 \\
\hline Cecropia leucoma Miq. & 7 & 1,2 & 0,32 & 0,031 & 0,14 & 66,7 & 0,69 & 0,38 \\
\hline Cecropia sciadophylla Mart. & 5 & 0,8 & 0,23 & 0,069 & 0,31 & 50,0 & 0,52 & 0,35 \\
\hline \multicolumn{9}{|l|}{ Celastraceae } \\
\hline Maytenus pruinosa Reiss. & 3 & 0,5 & 0,14 & 0,013 & 0,06 & 33,3 & 0,34 & 0,18 \\
\hline \multicolumn{9}{|l|}{ Chrysobalanaceae } \\
\hline Licania sp. & 13 & 2,2 & 0,59 & 0,078 & 0,34 & 66,7 & 0,69 & 0,54 \\
\hline Licania heteromorpha Benth. & 5 & 0,8 & 0,23 & 0,027 & 0,12 & 66,7 & 0,69 & 0,34 \\
\hline Couepia bracteosa Benth. & 1 & 0,2 & 0,05 & 0,004 & 0,02 & 16,7 & 0,17 & 0,08 \\
\hline \multicolumn{9}{|l|}{ Clusiaceae } \\
\hline Platonia insignis Mart. & 4 & 0,7 & 0,18 & 0,038 & 0,17 & 66,7 & 0,69 & 0,35 \\
\hline Vismia cayennensis (Jacq.) Pers. & 2 & 0,3 & 0,09 & 0,041 & 0,18 & 33,3 & 0,34 & 0,21 \\
\hline Rheedia acuminata Planch. \& Triana & 1 & 0,2 & 0,05 & 0,005 & 0,02 & 16,7 & 0,17 & 0,08 \\
\hline Vismia japurensis Reichardt & 1 & 0,2 & 0,05 & 0,002 & 0,01 & 16,7 & 0,17 & 0,08 \\
\hline Symphonia globulifera L.f. & 1 & 0,2 & 0,05 & 0,001 & 0,01 & 16,7 & 0,17 & 0,07 \\
\hline \multicolumn{9}{|l|}{ Combretaceae } \\
\hline Terminalia amazonia Exell in Pulle & 2 & 0,3 & 0,09 & 0,078 & 0,35 & 33,3 & 0,34 & 0,26 \\
\hline \multicolumn{9}{|l|}{ Ebenaceae } \\
\hline Diospyros sp. & 12 & 2,0 & 0,54 & 0,122 & 0,54 & 83,3 & 0,86 & 0,65 \\
\hline \multicolumn{9}{|l|}{ Euphorbiaceae } \\
\hline Joannesia heveoides Ducke & 4 & 0,7 & 0,18 & 0,153 & 0,68 & 33,3 & 0,34 & 0,40 \\
\hline Pausandra densiflora Lanj. & 8 & 1,3 & 0,36 & 0,024 & 0,11 & 66,7 & 0,69 & 0,39 \\
\hline Sagotia racemosa Baill. & 6 & 1,0 & 0,27 & 0,021 & 0,09 & 50,0 & 0,52 & 0,29 \\
\hline Glycydendron amazonicum Ducke & 4 & 0,7 & 0,18 & 0,025 & 0,11 & 50,0 & 0,52 & 0,27 \\
\hline Hevea sp. & 4 & 0,7 & 0,18 & 0,072 & 0,32 & 16,7 & 0,17 & 0,22 \\
\hline Sapium sp. & 2 & 0,3 & 0,09 & 0,009 & 0,04 & 33,3 & 0,34 & 0,16 \\
\hline Mabea sp. & 1 & 0,2 & 0,05 & 0,021 & 0,09 & 16,7 & 0,17 & 0,10 \\
\hline Drypetes variabilis Uittien & 1 & 0,2 & 0,05 & 0,003 & 0,01 & 16,7 & 0,17 & 0,08 \\
\hline \multicolumn{9}{|l|}{ Fabaceae } \\
\hline Eperua bijuga Mart. ex Benth. & 105 & 17,5 & 4,74 & 1,005 & 4,47 & 100,0 & 1,03 & 3,41 \\
\hline Inga sp. & 84 & 14,0 & 3,80 & 0,477 & 2,12 & 100,0 & 1,03 & 2,32 \\
\hline Tachigali myrmecophila Ducke & 19 & 3,2 & 0,86 & 0,435 & 1,93 & 100,0 & 1,03 & 1,27 \\
\hline Parkia sp. & 23 & 3,8 & 1,04 & 0,160 & 0,71 & 100,0 & 1,03 & 0,93 \\
\hline Ormosia sp. & 25 & 4,2 & 1,13 & 0,135 & 0,60 & 83,3 & 0,86 & 0,86 \\
\hline Alexa grandiflora Ducke & 11 & 1,8 & 0,50 & 0,236 & 1,05 & 100,0 & 1,03 & 0,86 \\
\hline Sclerolobium chrysophyllum Poepp. & 20 & 3,3 & 0,90 & 0,126 & 0,56 & 100,0 & 1,03 & 0,83 \\
\hline Piptadenia suaveolens Miq. & 13 & 2,2 & 0,59 & 0,227 & 1,01 & 83,3 & 0,86 & 0,82 \\
\hline Copaifera multijuga Hayne & 5 & 0,8 & 0,23 & 0,276 & 1,23 & 66,7 & 0,69 & 0,71 \\
\hline Sclerolobium guianense Benth. & 13 & 2,2 & 0,59 & 0,149 & 0,66 & 83,3 & 0,86 & 0,70 \\
\hline Parkia multijuga Benth. & 9 & 1,5 & 0,41 & 0,160 & 0,71 & 66,7 & 0,69 & 0,60 \\
\hline Pithecellobium racemosum Ducke & 11 & 1,8 & 0,50 & 0,085 & 0,38 & 83,3 & 0,86 & 0,58 \\
\hline Sclerolobium melinonii Harms & 6 & 1,0 & 0,27 & 0,124 & 0,55 & 66,7 & 0,69 & 0,50 \\
\hline Swartzia brachyrhachis Harms & 5 & 0,8 & 0,23 & 0,136 & 0,61 & 50,0 & 0,52 & 0,45 \\
\hline Eperua schomburgkiana Benth. & 7 & 1,2 & 0,32 & 0,084 & 0,37 & 50,0 & 0,52 & 0,40 \\
\hline Swartzia acuminata Willd. & 2 & 0,3 & 0,09 & 0,159 & 0,70 & 33,3 & 0,34 & 0,38 \\
\hline Swartzia corrugata Benth. & 5 & 0,8 & 0,23 & 0,128 & 0,57 & 33,3 & 0,34 & 0,38 \\
\hline Dialium guianense (Aubl.) Sandwith in A.C.Sm. & 4 & 0,7 & 0,18 & 0,057 & 0,25 & 50,0 & 0,52 & 0,32 \\
\hline Swartzia stipulifera Harms & 5 & 0,8 & 0,23 & 0,038 & 0,17 & 50,0 & 0,52 & 0,30 \\
\hline
\end{tabular}




\begin{tabular}{|c|c|c|c|c|c|c|c|c|}
\hline Famílias e Espécies & $\mathbf{N}$ & DA & DR & DoA & DoR & FA & FR & IVI\% \\
\hline Enterolobium schomburgkii Benth. & 2 & 0,3 & 0,09 & 0,098 & 0,43 & 33,3 & 0,34 & 0,29 \\
\hline Inga alba (Sw.) Willd. & 6 & 1,0 & 0,27 & 0,017 & 0,08 & 50,0 & 0,52 & 0,29 \\
\hline Abarema sp. & 5 & 0,8 & 0,23 & 0,021 & 0,09 & 50,0 & 0,52 & 0,28 \\
\hline Pterocarpus amazonicus Huber & 2 & 0,3 & 0,09 & 0,059 & 0,26 & 33,3 & 0,34 & 0,23 \\
\hline Stryphnodendron barbatimam Mart. & 3 & 0,5 & 0,14 & 0,033 & 0,15 & 33,3 & 0,34 & 0,21 \\
\hline Diplotropis purpurea (Rich.) Amshoff & 2 & 0,3 & 0,09 & 0,037 & 0,17 & 33,3 & 0,34 & 0,20 \\
\hline Sclerolobium sp. & 1 & 0,2 & 0,05 & 0,076 & 0,34 & 16,7 & 0,17 & 0,19 \\
\hline Dipteryx odorata Willd. & 3 & 0,5 & 0,14 & 0,014 & 0,06 & 33,3 & 0,34 & 0,18 \\
\hline Platymiscium filipes Benth. & 2 & 0,3 & 0,09 & 0,013 & 0,06 & 33,3 & 0,34 & 0,16 \\
\hline Tachigali sp. & 2 & 0,3 & 0,09 & 0,007 & 0,03 & 33,3 & 0,34 & 0,15 \\
\hline Ormosia discolor Spruce ex Benth. & 2 & 0,3 & 0,09 & 0,020 & 0,09 & 16,7 & 0,17 & 0,12 \\
\hline Hymenaea parvifolia Huber & 1 & 0,2 & 0,05 & 0,019 & 0,08 & 16,7 & 0,17 & 0,10 \\
\hline Bowdichia nitida Spruce & 1 & 0,2 & 0,05 & 0,013 & 0,06 & 16,7 & 0,17 & 0,09 \\
\hline Parkia pendula Benth. ex Walp. & 1 & 0,2 & 0,05 & 0,015 & 0,06 & 16,7 & 0,17 & 0,09 \\
\hline Enterolobium maximum Ducke & 1 & 0,2 & 0,05 & 0,009 & 0,04 & 16,7 & 0,17 & 0,09 \\
\hline Dimorphandra gardneriana Tul. & 1 & 0,2 & 0,05 & 0,007 & 0,03 & 16,7 & 0,17 & 0,08 \\
\hline Abarema mataybifolia (Sandwith) Barneby \& J.W.Grimes & 1 & 0,2 & 0,05 & 0,002 & 0,01 & 16,7 & 0,17 & 0,08 \\
\hline Hymenolobium excelsum Ducke & 1 & 0,2 & 0,05 & 0,002 & 0,01 & 16,7 & 0,17 & 0,08 \\
\hline \multicolumn{9}{|l|}{ Flacourtiaceae } \\
\hline Laetia procera (Poepp.) Eichler & 9 & 1,5 & 0,41 & 0,115 & 0,51 & 66,7 & 0,69 & 0,53 \\
\hline Lindackeria paraensis Kuhlm. & 8 & 1,3 & 0,36 & 0,085 & 0,38 & 66,7 & 0,69 & 0,48 \\
\hline Casearia javitensis H.B. \& K. & 5 & 0,8 & 0,23 & 0,019 & 0,08 & 50,0 & 0,52 & 0,28 \\
\hline Casearia decandra Jacq. & 3 & 0,5 & 0,14 & 0,010 & 0,04 & 33,3 & 0,34 & 0,17 \\
\hline Homalium sp. & 1 & 0,2 & 0,05 & 0,007 & 0,03 & 16,7 & 0,17 & 0,08 \\
\hline \multicolumn{9}{|l|}{ Goupiaceae } \\
\hline Goupia glabra Aubl. & 10 & 1,7 & 0,45 & 0,364 & 1,62 & 83,3 & 0,86 & 0,98 \\
\hline \multicolumn{9}{|l|}{ Humiriaceae } \\
\hline Sacoglottis amazonica Mart. & 2 & 0,3 & 0,09 & 0,051 & 0,23 & 33,3 & 0,34 & 0,22 \\
\hline Sacoglottis sp. & 2 & 0,3 & 0,09 & 0,026 & 0,12 & 33,3 & 0,34 & 0,18 \\
\hline Endopleura uchi (Huber) Cuatrec. & 1 & 0,2 & 0,05 & 0,051 & 0,23 & 16,7 & 0,17 & 0,15 \\
\hline \multicolumn{9}{|l|}{ Lauraceae } \\
\hline Ocotea sp. & 58 & 9,7 & 2,62 & 0,667 & 2,96 & 100,0 & 1,03 & 2,20 \\
\hline Licaria canella (Meisn.) Kosterm. & 28 & 4,7 & 1,27 & 0,172 & 0,76 & 100,0 & 1,03 & 1,02 \\
\hline Mezilaurus lindaviana Schwacke \& Mez & 5 & 0,8 & 0,23 & 0,053 & 0,24 & 50,0 & 0,52 & 0,33 \\
\hline Mezilaurus sp. & 1 & 0,2 & 0,05 & 0,144 & 0,64 & 16,7 & 0,17 & 0,29 \\
\hline Ocotea rubra Mez & 3 & 0,5 & 0,14 & 0,048 & 0,21 & 33,3 & 0,34 & 0,23 \\
\hline Aniba duckei Kosterm. & 2 & 0,3 & 0,09 & 0,006 & 0,02 & 16,7 & 0,17 & 0,10 \\
\hline Aniba canelilla Mez & 1 & 0,2 & 0,05 & 0,005 & 0,02 & 16,7 & 0,17 & 0,08 \\
\hline \multicolumn{9}{|l|}{ Lecythidaceae } \\
\hline Eschweilera blanchetiana Miers. & 85 & 14,2 & 3,84 & 0,784 & 3,48 & 100,0 & 1,03 & 2,79 \\
\hline Eschweilera amazonica R.Knuth & 68 & 11,3 & 3,07 & 0,516 & 2,29 & 100,0 & 1,03 & 2,13 \\
\hline Eschweilera amara Nied. & 51 & 8,5 & 2,30 & 0,573 & 2,54 & 100,0 & 1,03 & 1,96 \\
\hline Couratari oblongifolia Ducke \& R.Knuth & 25 & 4,2 & 1,13 & 0,261 & 1,16 & 100,0 & 1,03 & 1,11 \\
\hline Holopyxidium jarana Ducke & 7 & 1,2 & 0,32 & 0,170 & 0,76 & 83,3 & 0,86 & 0,64 \\
\hline Eschweilera odora Miers & 15 & 2,5 & 0,68 & 0,063 & 0,28 & 83,3 & 0,86 & 0,61 \\
\hline Bertholletia excelsa Humb. \& Bonpl. & 4 & 0,7 & 0,18 & 0,025 & 0,11 & 50,0 & 0,52 & 0,27 \\
\hline Lecythis usitata Miers & 2 & 0,3 & 0,09 & 0,097 & 0,43 & 16,7 & 0,17 & 0,23 \\
\hline Cariniana micrantha Ducke & 2 & 0,3 & 0,09 & 0,038 & 0,17 & 33,3 & 0,34 & 0,20 \\
\hline Eschweilera sp. & 1 & 0,2 & 0,05 & 0,004 & 0,02 & 16,7 & 0,17 & 0,08 \\
\hline
\end{tabular}




\begin{tabular}{|c|c|c|c|c|c|c|c|c|}
\hline Famílias e Espécies & $\mathbf{N}$ & DA & DR & DoA & DoR & FA & FR & IVI\% \\
\hline \multicolumn{9}{|l|}{ Malvaceae } \\
\hline Sterculia pilosa Ducke & 13 & 2,2 & 0,59 & 0,052 & 0,23 & 100,0 & 1,03 & 0,62 \\
\hline Theobroma speciosum Willd. & 13 & 2,2 & 0,59 & 0,034 & 0,15 & 100,0 & 1,03 & 0,59 \\
\hline Apeiba albiflora Ducke & 4 & 0,7 & 0,18 & 0,043 & 0,19 & 66,7 & 0,69 & 0,35 \\
\hline Sloanea froesii Earle Sm. & 5 & 0,8 & 0,23 & 0,018 & 0,08 & 50,0 & 0,52 & 0,27 \\
\hline Theobroma subincana Spruce ex Sagot & 3 & 0,5 & 0,14 & 0,026 & 0,11 & 50,0 & 0,52 & 0,26 \\
\hline Luehea speciosa Willd. & 1 & 0,2 & 0,05 & 0,090 & 0,40 & 16,7 & 0,17 & 0,21 \\
\hline \multicolumn{9}{|l|}{ Melastomataceae } \\
\hline Miconia sp. & 12 & 2,0 & 0,54 & 0,057 & 0,25 & 33,3 & 0,34 & 0,38 \\
\hline Mouriria plasschaerti Pulle & 2 & 0,3 & 0,09 & 0,016 & 0,07 & 33,3 & 0,34 & 0,17 \\
\hline Bellucia sp. & 2 & 0,3 & 0,09 & 0,009 & 0,04 & 16,7 & 0,17 & 0,10 \\
\hline \multicolumn{9}{|l|}{ Meliaceae } \\
\hline Carapa guianensis Aubl. & 25 & 4,2 & 1,13 & 0,328 & 1,46 & 100,0 & 1,03 & 1,21 \\
\hline Guarea kunthiana A.Juss. & 35 & 5,8 & 1,58 & 0,217 & 0,96 & 100,0 & 1,03 & 1,19 \\
\hline Trichilia sp. 2 & 39 & 6,5 & 1,76 & 0,115 & 0,51 & 100,0 & 1,03 & 1,10 \\
\hline Trichilia lecointei Ducke & 2 & 0,3 & 0,09 & 0,053 & 0,24 & 33,3 & 0,34 & 0,22 \\
\hline Cedrela odorata L. & 1 & 0,2 & 0,05 & 0,025 & 0,11 & 16,7 & 0,17 & 0,11 \\
\hline Trichilia sp. 1 & 1 & 0,2 & 0,05 & 0,006 & 0,03 & 16,7 & 0,17 & 0,08 \\
\hline Guarea sp. & 1 & 0,2 & 0,05 & 0,002 & 0,01 & 16,7 & 0,17 & 0,07 \\
\hline \multicolumn{9}{|l|}{ Moraceae } \\
\hline Perebea guianensis Aubl. & 33 & 5,5 & 1,49 & 0,147 & 0,65 & 100,0 & 1,03 & 1,06 \\
\hline Brosimum guianense Huber ex Ducke & 18 & 3,0 & 0,81 & 0,116 & 0,51 & 100,0 & 1,03 & 0,79 \\
\hline Sahagunia racemifera Huber & 16 & 2,7 & 0,72 & 0,067 & 0,30 & 100,0 & 1,03 & 0,68 \\
\hline Helicostylis pedunculata Benoist & 9 & 1,5 & 0,41 & 0,130 & 0,58 & 83,3 & 0,86 & 0,62 \\
\hline Brosimopsis obovata Ducke & 4 & 0,7 & 0,18 & 0,191 & 0,85 & 66,7 & 0,69 & 0,57 \\
\hline Bagassa guianensis Aubl. & 3 & 0,5 & 0,14 & 0,120 & 0,53 & 50,0 & 0,52 & 0,40 \\
\hline Perebea mollis (Poepp. \& Endl.) J.E.Huber & 9 & 1,5 & 0,41 & 0,061 & 0,27 & 50,0 & 0,52 & 0,40 \\
\hline Maquira sclerophylla (Ducke) C.C.Berg & 7 & 1,2 & 0,32 & 0,048 & 0,21 & 50,0 & 0,52 & 0,35 \\
\hline Clarisia racemosa Ruiz \& Pav. & 4 & 0,7 & 0,18 & 0,061 & 0,27 & 50,0 & 0,52 & 0,32 \\
\hline Brosimum lactescens (S.Moore) C.C.Berg & 4 & 0,7 & 0,18 & 0,021 & 0,09 & 50,0 & 0,52 & 0,26 \\
\hline Brosimum parinarioides Ducke & 3 & 0,5 & 0,14 & 0,017 & 0,07 & 50,0 & 0,52 & 0,24 \\
\hline Brosimum discolor Schott & 2 & 0,3 & 0,09 & 0,008 & 0,04 & 33,3 & 0,34 & 0,16 \\
\hline Castilla ulei Warb. & 1 & 0,2 & 0,05 & 0,005 & 0,02 & 16,7 & 0,17 & 0,08 \\
\hline \multicolumn{9}{|l|}{ Myristicaceae } \\
\hline Iryanthera juruensis Warb. & 16 & 2,7 & 0,72 & 0,343 & 1,52 & 100,0 & 1,03 & 1,09 \\
\hline Virola melinonii (Benoist) A.C.Sm. & 23 & 3,8 & 1,04 & 0,197 & 0,88 & 83,3 & 0,86 & 0,93 \\
\hline Virola cuspidata Warb. & 13 & 2,2 & 0,59 & 0,057 & 0,25 & 100,0 & 1,03 & 0,62 \\
\hline Virola divergens Ducke & 2 & 0,3 & 0,09 & 0,020 & 0,09 & 33,3 & 0,34 & 0,17 \\
\hline \multicolumn{9}{|l|}{ Myrtaceae } \\
\hline Eugenia lambertiana DC. & 31 & 5,2 & 1,40 & 0,131 & 0,58 & 100,0 & 1,03 & 1,01 \\
\hline Myrcia paivae 0.Berg & 8 & 1,3 & 0,36 & 0,027 & 0,12 & 66,7 & 0,69 & 0,39 \\
\hline Eugenia paraensis 0.Berg & 3 & 0,5 & 0,14 & 0,012 & 0,05 & 50,0 & 0,52 & 0,24 \\
\hline Myrcia sp. & 3 & 0,5 & 0,14 & 0,013 & 0,06 & 33,3 & 0,34 & 0,18 \\
\hline \multicolumn{9}{|l|}{ Nyctaginaceae } \\
\hline Neea sp. & 29 & 4,8 & 1,31 & 0,148 & 0,66 & 100,0 & 1,03 & 1,00 \\
\hline \multicolumn{9}{|l|}{ Olacaceae } \\
\hline Minquartia guianensis Aubl. & 17 & 2,8 & 0,77 & 0,408 & 1,81 & 100,0 & 1,03 & 1,21 \\
\hline \multicolumn{9}{|l|}{ Opiliaceae } \\
\hline Agonandra sp. & 1 & 0,2 & 0,05 & 0,005 & 0,02 & 16,7 & 0,17 & 0,08 \\
\hline
\end{tabular}




\begin{tabular}{|c|c|c|c|c|c|c|c|c|}
\hline Famílias e Espécies & $\mathrm{N}$ & DA & DR & DoA & DoR & FA & FR & IVI\% \\
\hline \multicolumn{9}{|l|}{ Polygonaceae } \\
\hline Coccoloba latifolia Lam. & 1 & 0,2 & 0,05 & 0,014 & 0,06 & 16,7 & 0,17 & 0,09 \\
\hline \multicolumn{9}{|l|}{ Quiinaceae } \\
\hline Lacunaria jenmani Ducke & 5 & 0,8 & 0,23 & 0,015 & 0,07 & 83,3 & 0,86 & 0,38 \\
\hline \multicolumn{9}{|l|}{ Rubiaceae } \\
\hline Duroia sprucei Rusby & 8 & 1,3 & 0,36 & 0,058 & 0,26 & 66,7 & 0,69 & 0,44 \\
\hline Duroia macrophylla Huber & 6 & 1,0 & 0,27 & 0,018 & 0,08 & 66,7 & 0,69 & 0,35 \\
\hline Chimarrhis turbinata DC. & 2 & 0,3 & 0,09 & 0,056 & 0,25 & 33,3 & 0,34 & 0,23 \\
\hline \multicolumn{9}{|l|}{ Sapindaceae } \\
\hline Talisia Iongifolia Radlk. & 15 & 2,5 & 0,68 & 0,080 & 0,35 & 100,0 & 1,03 & 0,69 \\
\hline Allophylus floribundus Radlk. & 1 & 0,2 & 0,05 & 0,005 & 0,02 & 16,7 & 0,17 & 0,08 \\
\hline \multicolumn{9}{|l|}{ Sapotaceae } \\
\hline Pouteria sp. 1 & 164 & 27,3 & 7,41 & 2,286 & 10,15 & 100,0 & 1,03 & 6,20 \\
\hline Manilkara huberi Standl. & 26 & 4,3 & 1,17 & 0,569 & 2,53 & 83,3 & 0,86 & 1,52 \\
\hline Pouteria sp. 2 & 33 & 5,5 & 1,49 & 0,190 & 0,85 & 100,0 & 1,03 & 1,12 \\
\hline Pouteria bilocularis (H.J.P.Winkl.) Baehni & 12 & 2,0 & 0,54 & 0,201 & 0,89 & 83,3 & 0,86 & 0,77 \\
\hline Manilkara paraensis Standl. & 5 & 0,8 & 0,23 & 0,285 & 1,27 & 50,0 & 0,52 & 0,67 \\
\hline Micropholis venulosa (Mart. \& Eichler ex Miq.) Pierre & 4 & 0,7 & 0,18 & 0,029 & 0,13 & 66,7 & 0,69 & 0,33 \\
\hline \multicolumn{9}{|l|}{ Simaroubaceae } \\
\hline Simarouba amara var. opaca Engl. in Engl. \& Prantl & 2 & 0,3 & 0,09 & 0,009 & 0,04 & 16,7 & 0,17 & 0,10 \\
\hline Simaba cedron Planch. & 1 & 0,2 & 0,05 & 0,003 & 0,01 & 16,7 & 0,17 & 0,08 \\
\hline \multicolumn{9}{|l|}{ Verbenaceae } \\
\hline Aegiphila sp. & 3 & 0,5 & 0,14 & 0,007 & 0,03 & 50,0 & 0,52 & 0,23 \\
\hline \multicolumn{9}{|l|}{ Violaceae } \\
\hline Rinorea guianensis (Aubl.) Kuntze & 163 & 27,2 & 7,37 & 1,053 & 4,68 & 100,0 & 1,03 & 4,36 \\
\hline Rinorea flavescens Kuntze & 27 & 4,5 & 1,22 & 0,072 & 0,32 & 83,3 & 0,86 & 0,80 \\
\hline Paypayrola grandiflora Tul. & 4 & 0,7 & 0,18 & 0,010 & 0,05 & 66,7 & 0,69 & 0,31 \\
\hline \multicolumn{9}{|l|}{ Vochysiaceae } \\
\hline Ruizterania albiflora (Warm.) Marc.-Berti & 3 & 0,5 & 0,14 & 0,086 & 0,38 & 33,3 & 0,34 & 0,29 \\
\hline Qualea sp. & 2 & 0,3 & 0,09 & 0,074 & 0,33 & 33,3 & 0,34 & 0,25 \\
\hline Erisma uncinatum Warm. & 1 & 0,2 & 0,05 & 0,033 & 0,15 & 16,7 & 0,17 & 0,12 \\
\hline Vochysia maxima Ducke & 2 & 0,3 & 0,09 & 0,004 & 0,02 & 16,7 & 0,17 & 0,09 \\
\hline \multicolumn{9}{|l|}{ Indeterminadas } \\
\hline Quataquisala* & 1 & 0,2 & 0,05 & 0,029 & 0,13 & 16,7 & 0,17 & 0,11 \\
\hline Trigueira* & 1 & 0,2 & 0,05 & 0,006 & 0,03 & 16,7 & 0,17 & 0,08 \\
\hline Tatarana* & 1 & 0,2 & 0,05 & 0,002 & 0,01 & 16,7 & 0,17 & 0,08 \\
\hline Valeta* & 1 & 0,2 & 0,05 & 0,003 & 0,01 & 16,7 & 0,17 & 0,08 \\
\hline
\end{tabular}

(*) Espécie identificada somente por nome popular.

Juntas, essas espécies representaram 32\% da densidade total observada. Por outro lado, o inventário florestal conduzido indicou um índice elevado de espécies localmente raras (i.e., espécies que ocorrem na amostragem com apenas um indivíduo). Do total de 186 espécies amostradas, 40 (21,5\%) foram representadas por uma única árvore.

A densidade estimada para o povoamento florestal foi de 369 árvores.ha ${ }^{-1}$, com uma área basal média de $22,5 \mathrm{~m}^{2} \cdot \mathrm{ha}^{-1}$ e um VCM médio de $229,5 \mathrm{~m}^{3} \cdot \mathrm{ha}^{-1}$. Na Figura 6 pode ser observada a distribuição diamétrica do conjunto total de indivíduos arbóreos, em classes de diâmetro com intervalos de $5 \mathrm{~cm}$. A estrutura diamétrica do povoamento seguiu o padrão usual de florestas tropicais inequiâneas (J-invertido), sugerindo a existência de um balanço entre o recrutamento e a mortalidade de árvores. Foi possível visualizar uma alta concentração de árvores nas primeiras classes de diâmetro (85\% até o limite de $35 \mathrm{~cm}$ ), com uma redução exponencial dessa concentração no sentido das classes de maior diâmetro.

$\mathrm{Na}$ Figura 7 é apresentada a classificação das 50 espécies com maior IVI, quanto ao potencial de aproveitamento no mercado madeireiro e comportamento ecológico. Entre as espécies caracterizadas, $63 \%$ pertenceram ao grupo que é 
atualmente comercializado ou que apresenta características favoráveis à comercialização, em termos de dimensões e qualidade da madeira. Dessa forma, o povoamento apresentou um elevado potencial para exploração, corroborando os resultados encontrados por Silva et al. (1985). Quanto ao comportamento ecológico, foi possível observar que $78 \%$ das espécies caracterizadas pertenceram ao grupo das tolerantes à sombra. Este resultado é um indicativo de que o povoamento florestal estudado encontra-se em processo avançado de sucessão, apresentando uma configuração volumétrica em condiçãao de equilíbrio dinâmico.

\section{CARACTERIZAÇÃO DAS PARCELAS AMOSTRAIS}

Na Tabela 2 é apresentado, para cada parcela amostral, o número total de indivíduos arbóreos, famílias e espécies inventariadas, além do valor do índice de Shannon-Weaver. A densidade das parcelas diferiu em até 83 árvores por hectare, com o menor valor observado para a parcela P3 (325 árvores. $h^{-1}{ }^{-1}$. No que diz respeito à diversidade, a parcela com menor riqueza florística (P4) apresentou 93 espécies distribuídas em 32 famílias, ao passo que a parcela com maior riqueza (P1) apresentou 103 espécies distribuídas em 40 famílias. $\mathrm{O}$ índice de Shannon-Weaver indicou alta heterogeneidade florística em todas as parcelas inventariadas. Apesar dos valores de $H^{\prime}$ apresentarem baixa amplitude de variação (máximo

Tabela 2 - Número total de árvores, famílias e espécies de cada parcela amostral do inventário florestal, com o respectivo valor do índice de ShannonWeaver $\left(\mathrm{H}^{\prime}\right)$.

\begin{tabular}{lllll}
\hline Parcela & Árvores & Famílias & Espécies & $\boldsymbol{H}^{\prime}$ \\
\hline P1 & 408 & 40 & 103 & $4,04^{\mathrm{a}}$ \\
P2 & 355 & 34 & 93 & 3,80 \\
P3 & 325 & 35 & 94 & $3,94^{\mathrm{b}}$ \\
P4 & 353 & 32 & 93 & $3,97^{\mathrm{bc}}$ \\
P5 & 385 & 32 & 97 & 3,89 \\
P6 & 387 & 34 & 101 & $4,01^{\mathrm{ac}}$ \\
\hline
\end{tabular}

$\left.{ }^{(a b c}\right)$ Valores seguidos das mesmas letras não diferem estatisticamente ao nível de $1 \%$ de significância.

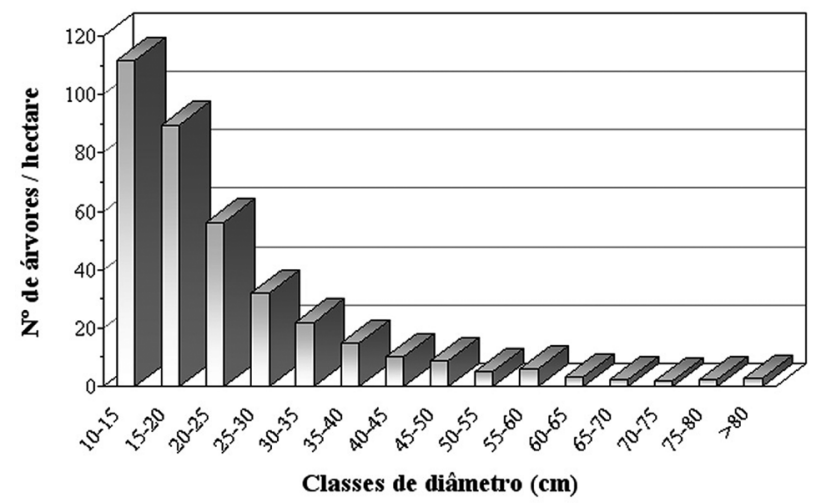

Figura 6 - Distribuição diamétrica dos 2.213 indivíduos arbóreos amostrados no inventário florestal.

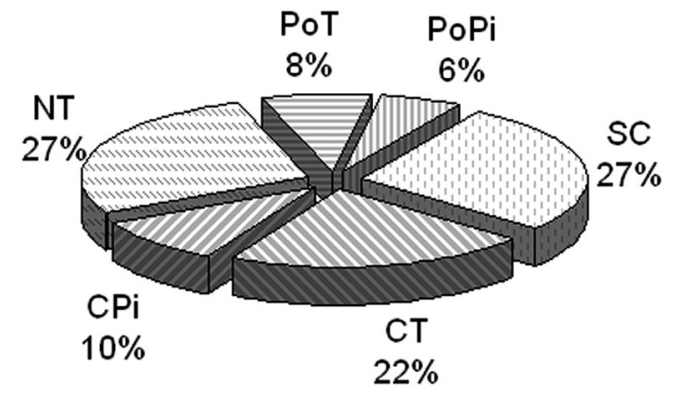

Figura 7 - Potencial de aproveitamento no mercado madeireiro $(C=$ comercial, $\mathrm{Po}=$ potencial e $\mathrm{N}=$ não comercial) e comportamento ecológico $(\mathrm{Pi}=$ pioneira e $\mathrm{T}=$ tolerante) das 50 espécies amostradas com maior IVI (SC = sem caracterização).

de $6,3 \%$ em relação ao menor valor), o teste de Hutcheson evidenciou diferenças significativas $(p<0,01)$ entre a diversidade de praticamente todas as parcelas. Os únicos pares estatisticamente iguais foram: P1/P6, P3/P4 e P4/P6.

No dendrograma da Figura 8 é apresentado o resultado da análise de agrupamento (UPGMA) baseada no índice de similaridade de Jaccard. Para distinção dos grupos formados, foi aplicado um nível de corte de $25 \%$ no eixo de escala do dendrograma, conforme recomendado por Mueller-Dombois \& Ellenberg (1974). Adotando-se este limiar $\left(S_{i j}=0,48\right)$, as parcelas inventariadas foram separadas em 3 grupos distintos: um formado pelo conjunto das parcelas P2, P3, P4 e P5, correspondendo exatamente àquelas com menor índice de Shannon-Weaver (Tabela 2); um formado pela parcela P1; e um último formado pela parcela P6. Contudo, é importante notar que o agrupamento das parcelas $\mathrm{P} 1$ e $\mathrm{P} 6$ ocorreu em um nível de similaridade bastante próximo daquele estabelecido como nível de corte.

Na Figura 9 são apresentadas as médias de DAP e HT de cada tratamento da ANOVA, com os respectivos intervalos de confiança computados a 95\%. Os valores médios registrados para os tratamentos apresentaram amplitude de variação de 4,0 $\mathrm{cm}$ para o DAP e de 2,6 m para a HT. Os resultados da estatística $F$ indicaram a ocorrência de médias de HT com diferenças significativas $(\mathrm{p}<0,05)$. Com relação ao DAP, uma vez que foram produzidos intervalos de confiança mais amplos (maior erro padrão), a ANOVA indicou que as médias dos tratamentos não diferiram significativamente.

Mediante o teste de comparação múltipla de Tukey, verificou-se que a média da HT da parcela $\mathrm{P} 6(14,18 \pm 1,01$ $\mathrm{m})$ diferiu da média das parcelas $\mathrm{P} 4(16,55 \pm 1,01 \mathrm{~m})$ e $\mathrm{P} 5$ $(16,74 \pm 1,01 \mathrm{~m})$, ao nível de $5 \%$ de significância. As demais médias observadas não apresentaram diferenças significativas. Quanto à avaliação das suposiçōes da ANOVA, não foram 


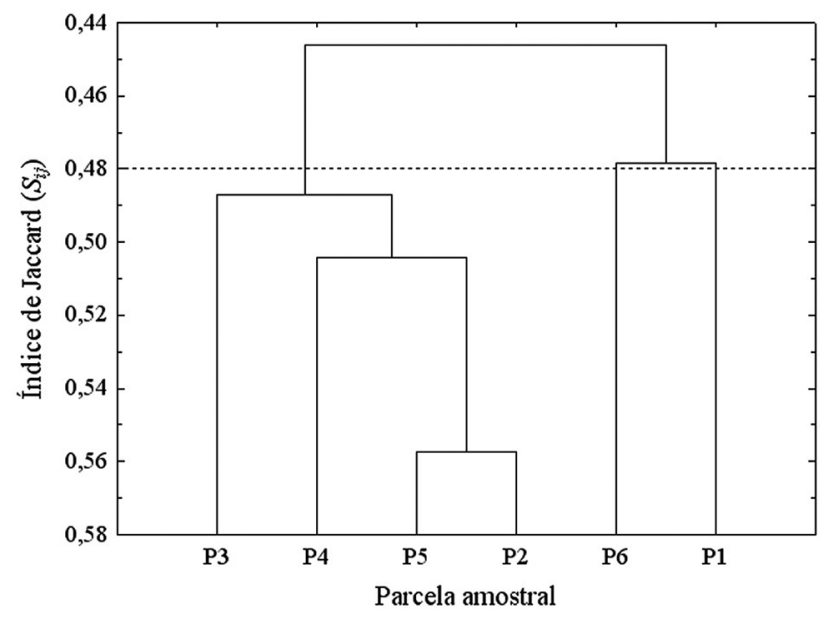

Figura 8 - Dendrograma de similaridade florística entre as diferentes parcelas do inventário florestal. A linha horizontal pontilhada representa 0 nível de corte de $25 \%$.

observados problemas no que diz respeito à adequação do conjunto de dados. Com o teste de Moran foi confirmada a ausência de autocorrelação espacial entre as observaçôes de cada tratamento $(\mathrm{p}>0,05)$. Pelo teste de Shapiro-Wilk foi observado que a variável HT se apresentou normalmente distribuída nos tratamentos ( $p>0,05)$. Por fim, o teste de Bartlett sugeriu que as variâncias dos diferentes tratamentos poderiam ser as mesmas $(\mathrm{p}>0,05)$.

Para auxiliar a interpretação da estrutura nas diferentes parcelas amostrais, são apresentadas na Figura 10 as respectivas distribuições diamétricas, os valores médios de HT por classe de DAP e os valores estimados de VCM. Apesar de não terem sido registradas diferenças estatísticas significativas entre o DAP médio das parcelas, as distribuiçōes diamétricas sugeriram a ocorrência de certa variabilidade nos padrões estruturais. As parcelas $\mathrm{P} 2$ e $\mathrm{P} 3$ foram as que apresentaram o componente arbóreo com a estrutura mais desenvolvida, além dos maiores valores de VCM (280,3 e 240,2 $\mathrm{m}^{3}$.ha ${ }^{-1}$, respectivamente). Nas distribuições destas parcelas pôde-se visualizar, em comparação às demais, um maior balanceamento das freqüências entre as diferentes classes de DAP, com uma concentração de árvores menos acentuada nos primeiros intervalos de diâmetro.

Entre as parcelas do inventário florestal, a P6 foi a que apresentou a estrutura mais diferenciada. Nessa parcela foi registrada a maior concentração de árvores nas primeiras classes de DAP ( $89 \%$ até o limite de $35 \mathrm{~cm}$ ) e o menor valor de VCM $\left(182,6 \mathrm{~m}^{3} \cdot \mathrm{ha}^{-1}\right)$. Em adição, assim como na ANOVA, foi observado um comportamento atípico nos valores de HT. Os indivíduos arbóreos com DAP entre 45 e $70 \mathrm{~cm}$ apresentaram,
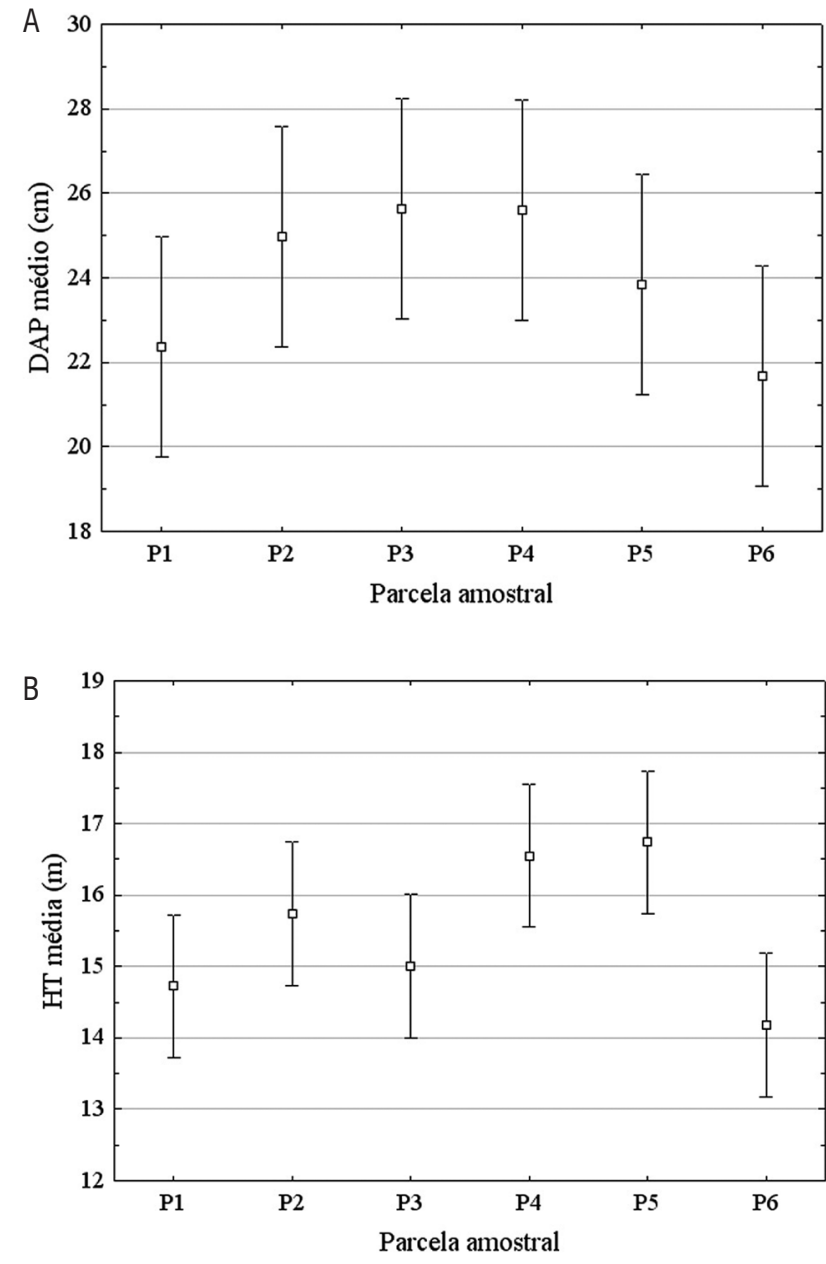

Figura 9 - Resultado da ANOVA para o DAP (a) e HT (b) das parcelas amostrais. As barras verticais denotam intervalos de confiança para a média, ao nível de $95 \%$.

em média, menores alturas totais do que aquelas observadas nas demais parcelas amostrais.

É possível que as diferenças relatadas sejam resultantes da composição florística específica da parcela P6. Como demonstrado no dendrograma da Figura 8, essa parcela apresentou uma composição distinta daquela observada nas demais parcelas amostrais. Alia-se ainda o fato da área estar localizada num bloco de exploração manejado cerca de cinco anos antes do inventário. Tal fato pode traduzir, em parte, um maior ingresso de indivíduos arbóreos nos estratos inferiores dessa parcela e, conseqüentemente, uma maior competitividade durante a ocupação das clareiras no processo de regeneração. No que diz respeito às parcelas P1, P4 e P5, cabe ainda ressaltar que as mesmas apresentaram estruturas diamétricas relativamente similares.

\section{CONCLUSÕES}




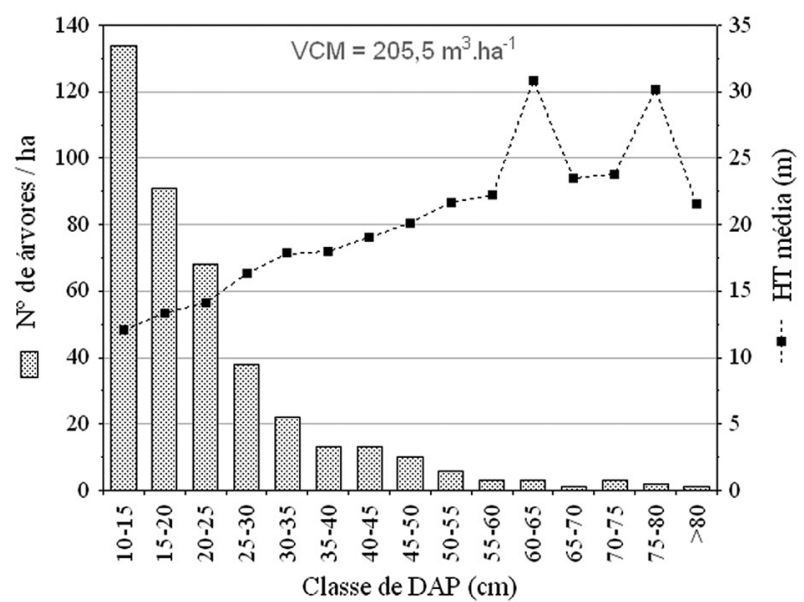

P1

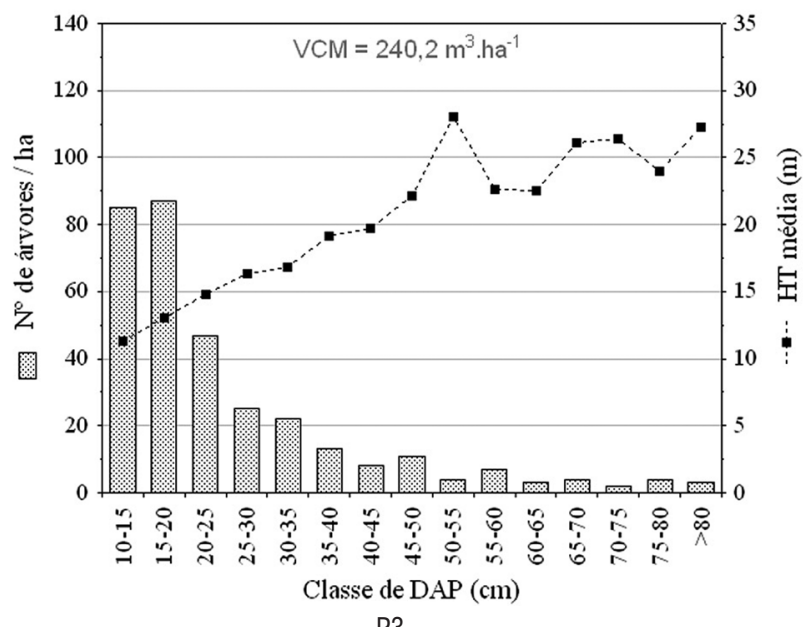

P3

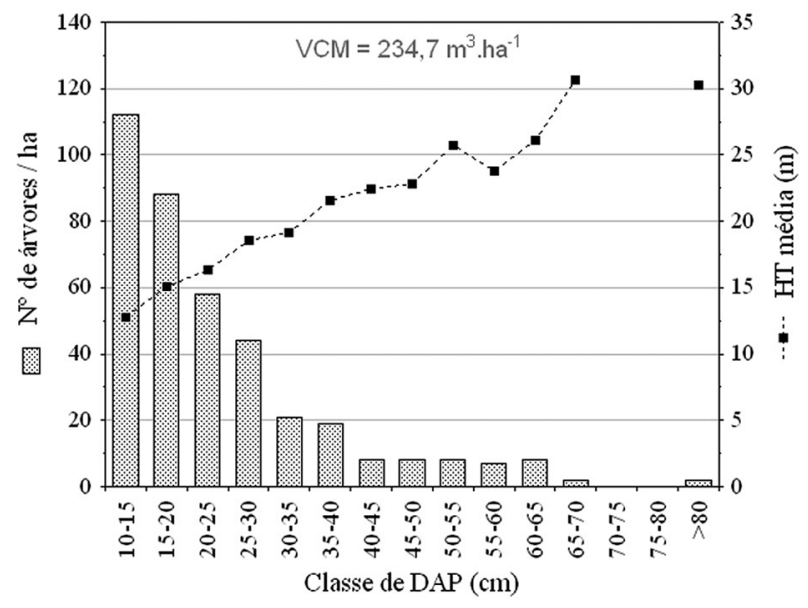

P5

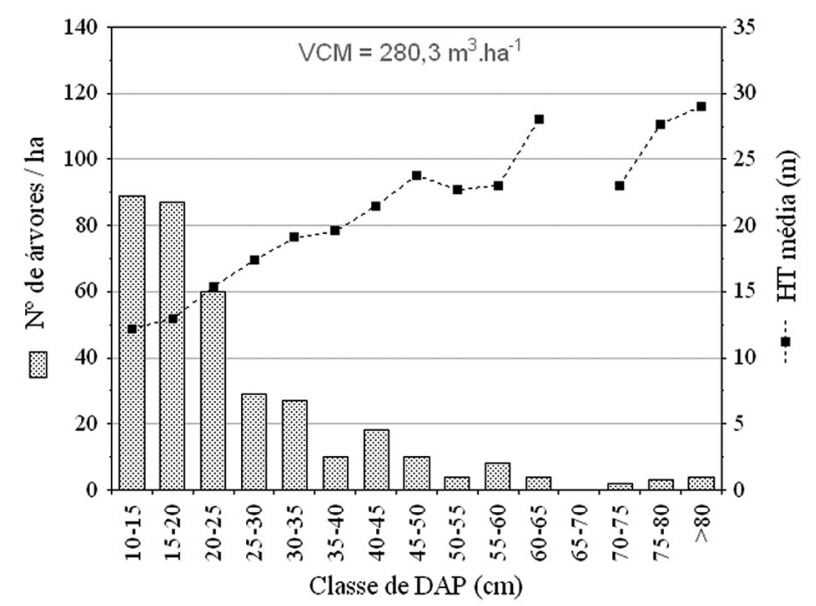

P2
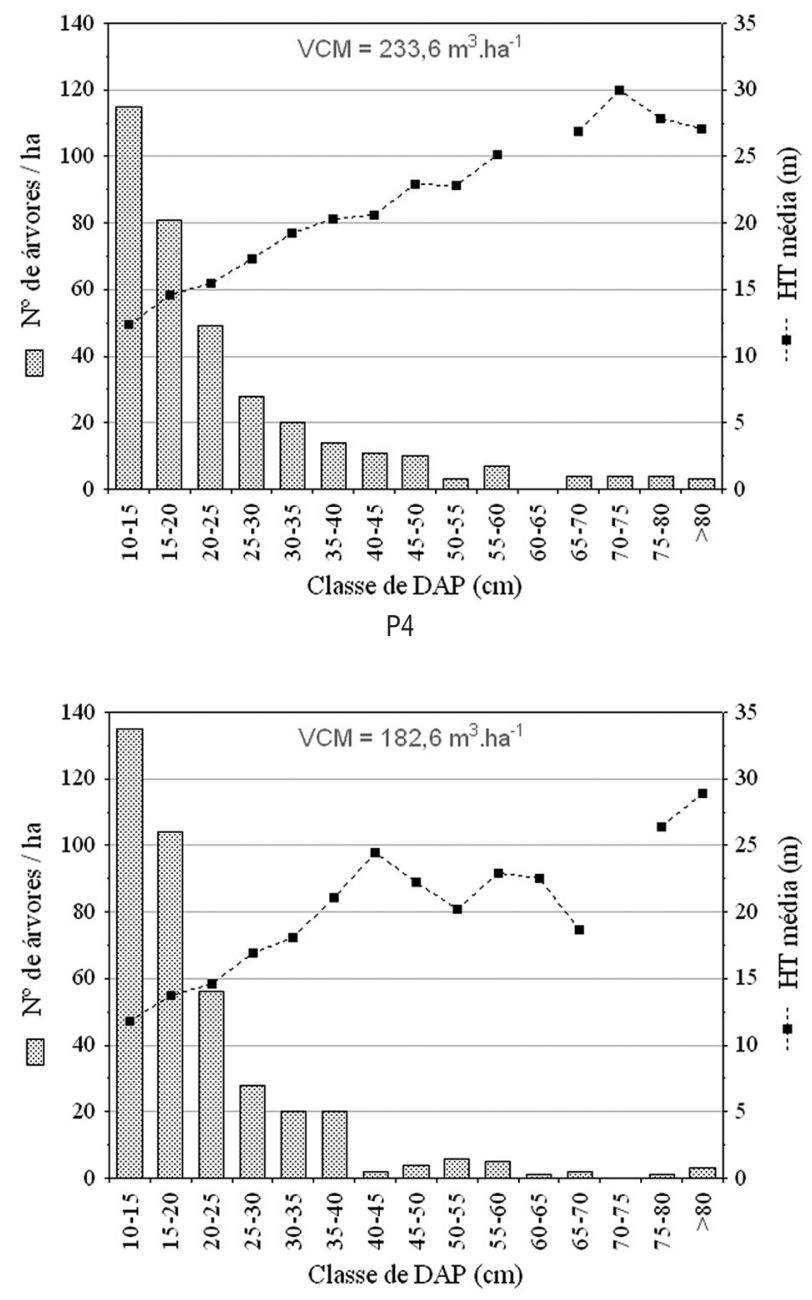

P6

Figura 10 - Distribuição diamétrica, valores médios de HT por classe de DAP e valores de VCM estimados para cada parcela amostral. 
Os resultados deste trabalho permitem concluir que a unidade de manejo florestal estudada apresenta uma elevada diversidade florística no componente arbóreo, indicando uma manutenção do número de espécies após a exploração. Entretanto, observou-se que o povoamento é caracterizado pela concentração de uma grande quantidade de indivíduos e espécies em poucas famílias botânicas, bem como por um número elevado de espécies localmente raras. Tal fato pode estar relacionado à atividade de exploração madeireira, sendo vinculado às práticas de manejo adotadas.

A estrutura diamétrica do povoamento seguiu o padrão usual de florestas tropicais inequiâneas, indicando a existência de um balanço entre o recrutamento e a mortalidade de indivíduos. Isso sugere sustentabilidade da produção volumétrica na unidade de manejo, a qual é caracterizada por uma baixa densidade de exploração. Desse modo, o povoamento apresenta um elevado potencial para a exploração madeireira, considerando-se claro a manutenção da diversidade de espécies e de um estoque volumétrico apropriado às funçôes ecológicas da floresta.

A análise das variaçôes florístico-estruturais entre parcelas amostrais evidenciou diferenças significativas quanto à diversidade e à similaridade de espécies. Com base na análise de variância, também foram observadas diferenças significativas entre os valores médios de altura total. Adicionalmente, observou-se certa variabilidade nos padrōes estruturais em termos de distribuição diamétrica, valores médios de altura total por classe de diâmetro e valores estimados de volume comercial de madeira.

\section{AGRADECIMENTOS}

Os autores agradecem a CAPES e ao CNPq pela concessão das bolsas de mestrado e de produtividade em pesquisa; ao INPE, através do Projeto MAPSAR, pelo suporte institucional; ao LBA/Santarém, pelo apoio logístico durante o trabalho de campo; ao IBAMA, nas pessoas de Gustavo $S$. C. de Pinho e Daniel Cohenca, pelo fornecimento de dados e informaçōes; ao identificador botânico Sr. Erly Pedroso e aos ajudantes Johnny e Raimundo, pela assistência em campo e conhecimentos compartilhados; e aos colegas Paulo César G. de Albuquerque (INPE), Cláudia Cristina dos Santos (INPE) e Marcos A. T. Elmiro (UFMG), pelo auxílio técnico no georreferenciamento das parcelas amostrais.

\section{BIBLIOGRAFIA CITADA}

Anselin, L. 1996. The Moran scatterplot as an ESDA tool to assess local instability in spatial association. In: Fisher, M.; Scholten, H.J.; Unwin, D. (Eds). Spatial Analytical Perspectives on GIS GISDATA 4. Taylor \& Francis, London, England. p. 111-126.
APG (Angiosperm Phylogeny Group). 1998. An ordinal classification for the families of flowering plants. 1998. Annals of Missouri Botanical Garden, 85(4): 531-553.

Asner, G.P.; Knapp, D.E.; Broadbent, E.N.; Oliveira, P.J.C.; Keller, M.; Silva, J.N. 2005. Selective logging in the Brazilian Amazon. Science, 310(5747): 480-482.

Barros, P.L.C. 1980. Estudo das distribuiçôes diamétricas da floresta do Planalto Tapajós - Pará. Dissertação de Mestrado, Universidade Federal do Paraná, Curitiba, Paraná. 123pp.

Barros, A.C.; Veríssimo, A. 2002. A expansão madeireira na Amazônia: impactos e perspectivas para o desenvolvimento sustentável no Pará. 2.ed. Imazon, Belém, Pará. 166pp.

BRASIL. 2002. Lei n. 9.985, de 18 de Junho de 2000: Sistema Nacional de Unidades de Conservação da Natureza (SNUC). 2.ed. MMA, Brasília, Distrito Federal. 52pp.

Brown, I.F.; Nepstad, D.C.; Pires, I.O.; Luz L.M.; Alechandre, A.S. 1992. Carbon storage and land-use in extractive reserves, Acre, Brazil. Environmental Conservation, 19(14): 307-315.

Brown, S. 1997. Estimating biomass and biomass change of tropical forests: a primer (FAO Forestry Paper - 134). FAO, Rome, Italy. $55 \mathrm{pp}$.

Cailliez, F. 1977. Inventaire de preinvestissement de la Forêt Nacionale du Tapajos. PRODEPEF, Brasília, Distrito Federal. 42pp.

Carvalho Jr., J.A.; Santos, J.M.; Santos, J.C.; Leitão, M.M.; Higuchi, N. 1995. A tropical rainforest clearing experiment by biomass burning in the Manaus region. Atmospheric Environment, 29(17): 2301-2309.

Curtis, J.T.; McIntosh, R.P. 1951. An upland forest continuum in the prairie-forest border region of Wisconsin. Ecology, 32(3): 476-496.

Dobson, M.C.; Ulaby, F.T.; Pierce, L.E.; Sharik, T.L.; Bergen, K.M.; Kellndorfer, J.M.; Kendra, J.R.; Li, E.; Lin, Y.C.; Nashashibi, A.; Sarabandi, K.; Siqueira, P. 1995. Estimation of forest biophysical characteristics in Northern Michigan with SIR-C/X-SAR. IEEE Transactions on Geoscience and Remote Sensing, 33(4): 877-895.

Dubois, J. 1976. Preliminary forest management guidelines for the National Forest of Tapajós. FAO/PRODEPEF, Belém, Pará. 41pp.

Espírito-Santo, F.D.B.; Shimabukuro, Y.E.; Aragão, L.E.O.C.; Machado, E.L.M. 2005. Análise da composição florística e fitossociológica da Floresta Nacional do Tapajós com o apoio geográfico de imagens de satélites. Acta Amazonica, 35(2): 155-173.

Foody, G.M.; Boyd, D.S.; Cutler, M.E.J. 2003. Predictive relations of tropical forest biomass from Landsat TM data and their transferability between regions. Remote Sensing of Environment, 85(4): 463-474.

Guimarães, E.G.T.; Pyle, E.H. 1999. Levantamento florestal de 20 ha na Floresta Nacional do Tapajós. LBA, Santarém, Pará. 30pp.

Hair, J.F.; Anderson, R.E.; Tatham, R.L.; Black, W. 1998. Multivariate data analysis. 5.ed. Prentice Hall, Upper Saddle River, NJ, USA. 730pp. 
Higuchi, N.; Carvalho Jr., J.A. 1994. Fitomassa e conteúdo de carbono de espécies arbóreas da Amazônia. In: Seminário Emissão x Seqüestro de CO2: uma nova oportunidade de negócios para o Brasil. Anais... Companhia Vale do Rio Doce, Rio de Janeiro, RJ. p. 125-153.

Hoekman, D.H.; Quiñones, M.J. 2000. Land cover type and biomass classification using AirSAR data for evaluation of monitoring scenarios in the Colombian Amazon. IEEE Transactions on Geoscience and Remote Sensing, 38(2): 685-696.

Hutcheson, K. 1970. A test for comparing diversities based on the Shannon formula. Journal of Theory Biology, 29(1): 151-154.

Hyyppa, J.; Hyyppa, H.; Inkinen, M.; Engdahl, M.; Linko, S.; Zhu, Y. 2000. Accuracy comparison of various remote sensing data sources in the retrieval of forest stand attributes. Forest Ecology and Management, 128(1-2): 109-120.

IBAMA (Instituto Brasileiro do Meio Ambiente e dos Recursos Naturais Renováveis). 2004. Floresta Nacional do Tapajós - Plano de Manejo. IBAMA, Belterra, Pará. 373pp.

IBAMA/PNUD (Instituto Brasileiro do Meio Ambiente e dos Recursos Naturais Renováveis/Programa das Nações Unidas para o Desenvolvimento). 1997. Plano de manejo florestal da Floresta Nacional do Tapajós, Pará, Brasil. IBAMA, Brasília, Distrito Federal. 109pp.

IBDF. 1983. Inventário florestal preliminar da Floresta Nacional do Tapajós, Estado do Pará: florestas de flanco e de declive. IBDF/ UFV, Viçosa, Minas Gerais. 140pp.

INPE (Instituto Nacional de Pesquisas Espaciais), 2007. Projeto PRODES: monitoramento da floresta amazônica brasileira por satélite (http://www.obt.inpe.br/prodes/). Acesso: 30/05/07.

Jardim, F.C.S.; Hosokawa, R.T. 1986. Estrutura da floresta equatorial úmida da Estação Experimental de Silvicultura Tropical do INPA. Acta Amazonica, 16/17(único): 411-508.

Le Toan, T; Beaudoin, A.; Riom, J.; Guyon, D. 1992. Relating forest biomass to SAR data. IEEE Transactions on Geoscience and Remote Sensing, 30(2): 403-411.

Luckman, A.; Baker, J.; Kuplich, T.M.; Yanasse, C.C.F.; Frery, A.C. 1997. A study of the relationship between radar backscatter and regenerating tropical forest biomass for spaceborne SAR instruments. Remote Sensing of Environment, 60(1): 1-13.

Magurran, A. 1988. Ecological diversity and its measurement. Princeton University Press, Princeton, NJ, USA. 179pp.

Mather, P.M. 1999. Computer processing of remotely-sensed images: an introduction. 2.ed. John Wiley and Sons, Inc., Chichester, England. 292pp.

Mueller-Dombois, D.; Ellenberg, G.H. 1974. Aims and methods of vegetation ecology. John Wiley and Sons, Inc., Chichester, England. 547pp.
Nepstad, D.C.; Veríssimo, A.; Alencar, A.; Nobre, C.; Lima, E.; Lefebvre, P.; Schlesinger, P.; Potter, C.; Moutinho, P.; Mendoza, E.; Cochrane, M.; Brooks, V. 1999. Large-scale impoverishment of Amazonian forests by logging and fire. Nature, 398(6): 505508.

Nobre, C.A. 1991. Amazonian deforestation model and regional climate change. Journal of Climate, 4(10): 957-988.

Oliveira, L.C. 2005. Efeito da exploração da madeira e de diferentes intensidades de desbastes sobre a dinâmica da vegetação de uma área de 136ha na Floresta Nacional do Tapajós. Tese de Doutorado, Universidade de São Paulo (Escola Superior de Agricultura Luíz de Queiroz), Piracicaba, São Paulo. 183pp.

Queiroz, W.T. 1984. Análise de fatores ("factor analysis") pelo método da máxima verossimilhança: aplicação ao estudo da estrutura de florestas tropicais. Tese de Doutorado, Universidade de São Paulo (Escola Superior de Agricultura Luiz de Queiroz), Piracicaba, São Paulo. 112pp.

Santos, J.R.; Freitas, C.C.; Araujo, L.S.; Dutra, L.V.; Mura, J.C.; Gama, F.F.; Soler, L.S.; Sant'Anna, S.J.S. 2003. Airborne P-band SAR applied to the aboveground biomass studies in the Brazilian tropical rainforest. Remote Sensing of Environment, 87(4): 482-493.

Shapiro, S.S.; Wilk, M.B.; Chen, H.J. 1968. A comparative study of various tests of normality. Journal of the American Statistical Association, 63(324): 1343-1372.

Silva, J.N.M.; Carvalho, J.O.P.; Lopes, J.C.A. 1985. Inventário florestal de uma área experimental na Floresta Nacional do Tapajós. Boletim de Pesquisa Florestal, (10-11): 38-110.

Sneath, P.H.A.; Sokal, R.R. 1973. Numerical Taxonomy: the principles and practice of numerical classification. W.H. Freeman and Company, San Francisco, CA, USA. 573pp.

Uhl, C.; Veríssimo, A.; Mattos, M.M.; Brandino, Z.; Vieira, I.C.G. 1991. Social, economic, and ecological consequences of selective logging in an Amazon frontier: the case of Tailândia. Forest Ecology and Management, 46(3-4): 243-273.

Veloso, H.P.; Rangel Filho, A.L.R.; Lima, J.C.A. 1991. Classificação da vegetação brasileira, adaptada a um sistema universal. IBGE, Rio de Janeiro, Rio de Janeiro. 123pp.

Veríssimo, A.; Barreto, P.; Mattos, M.; Tarifa, R.; Uhl, C. 1992. Logging impacts and prospects for sustainable forest management in an old Amazonian frontier: the case of Paragominas. Forest Ecology and Management, 55(1-4): 169-199.

Winer, B.J.; Brown, D.R.; Michels, K.M. 1991. Statistical principals in experimental design. 3.ed. McGraw-Hill, New York, NY, USA.

Recebido em 03/07/2007

Aceito em 03/03/2008 